\title{
Temporal Variability of the Charlotte (Sub)Urban Heat Island
}

\author{
Matthew D. Eastin, Matthew Baber, Adrienne Boucher, Sofia Di Bari, \\ RYAN HUBLER, BRANDY STIMAC-SPALDING, AND THOMAS WINESETT \\ Department of Geography and Earth Sciences, University of North Carolina at Charlotte, Charlotte, North Carolina
}

(Manuscript received 10 April 2017, in final form 15 August 2017)

\begin{abstract}
A multiscale temporal analysis of the urban heat island (UHI) for a large, rapidly growing, subtropical city (Charlotte, North Carolina) is conducted using hourly surface observations from a regional network of 12 weather and air-quality stations over a 5 -yr period and monthly mean surface temperatures from two stations over a 40-yr period. Each station was classified as urban, suburban, or rural after detailed site analysis. During the 5-yr period, from temperature differences between the most central urban site and the rural reference site, over $70 \%$ of nights exhibited prominent nocturnal UHIs. The most intense UHIs occurred on winter nights with light winds, clear skies, low humidity, strong low-level stability, and no precipitation or frontal passage. The UHI maxima occurred either just after sunset or near sunrise. Maximum urban and rural cooling rates occurred within a few hours of sunset, but rural maxima were larger and preceded (by $1-2 \mathrm{~h}$ ) the urban maxima. Daily variations in nocturnal mean UHI intensity exhibited significant positive correlations with cloud-base height, atmospheric stability, $\mathrm{NO}_{2}$ concentration, and total solar radiation and significant negative correlations with relative humidity, wind speed, and cloud cover. When optimal weather for UHI development was present, UHIs were more intense on weekdays than on weekends. During the 40-yr period, an appreciable positive trend in UHI intensity occurred. These results support the notion that weather, air pollution, and urban form change can significantly modulate UHI intensities. Similarities and differences between the Charlotte UHI and those observed in similar cities are discussed.
\end{abstract}

\section{Introduction}

The global population is becoming more urbanized. To date, more than $50 \%$ of the human population lives in urban areas, yet urban areas cover less than $1 \%$ of the global land area (Mills 2007). The urbanization process involves, in part, converting natural/vegetated surfaces to more impervious surfaces with different thermal, moisture, and radiative properties. Such changes significantly alter the local energy balance with regards to the net radiation, heat storage, and the partitioning of latent and sensible heat fluxes. Moreover, recent numerical simulations have demonstrated that climate change induced by land-cover/land-use (LULC) change through urbanization may be as important as greenhouse gas-induced climate change at regional scales (Mahmood et al. 2014; Georgescu 2015).

One of the most widely studied aspects of urban climate change is the urban heat island (UHI), whereby surface (or canopy layer) temperatures in urban areas are up to $10^{\circ} \mathrm{C}$

Corresponding author: Matthew D. Eastin,mdeastin@uncc.edu warmer than the surrounding rural areas. UHIs are largely nocturnal phenomena caused by significant differences in urban/rural boundary layer cooling after sunset (Oke 1982). However, on any given night, UHIs result from a complex balance among multiple local factors that control the nocturnal cooling rates, including meteorological conditions, urban form, and human activity. Given that such factors are also influenced by climate, season, and geography, the governing UHI controls, and their relative importance, are often unique to each city (Grimmond 2007).

Prior studies have documented a wide range of controlling factors. With regard to meteorological controls, wind speed and cloud cover are often deemed the most important (e.g., Runnalls and Oke 2000; Morris et al. 2001), but other potentially significant atmospheric controls include humidity (Hoffmann et al. 2012), stability (Holmer et al. 2013), solar radiation (Steeneveld et al. 2011), synoptic circulations (Hoffmann and Schlünzen 2013), and local circulations such as land-sea breezes (Acero et al. 2013), mountain-valley flows (Giovannini et al. 2011), or low-level jet streams (Hu et al. 2013). Significant controls due to urban form are the sky-view factor 
(SVF) derived from canyon geometry (Oke et al. 1991), the urban fabric thermal/radiative properties (Grimmond and Oke 1995), and the LULC distribution (Hart and Sailor 2009). Controls due to human activity include anthropogenic heat release (Sailor and $\mathrm{Lu} 2004$ ) and air pollution (Simmonds and Keay 1997). Finally, appreciable differences in annual mean UHI intensity among cities have been attributed to differences in population (Oke 1973) and regional climate (Wienert and Kuttler 2005; Roth 2007). Overall, the most intense UHIs are often observed in the urban core of large midlatitude cities on warm nights with clear skies, light winds, low humidity, strong low-level stability, and an anticyclone overhead.

In turn, intense UHIs can produce appreciable ecologic and human impacts across a region. For example, many studies have documented UHI-initiated/enhanced precipitation over and downwind of urban areas during the warm season (Shepherd 2005; Ashley et al. 2012), which can influence regional flash flood risk, water resource management, and agriculture (Collier 2006). Additional impacts include modified energy consumption (Memon et al. 2008), increased concern for human comfort/health during UHI-enhanced heat waves (Steeneveld et al. 2011; Petitti et al. 2016), and modification of local ecology through reduced species richness (Grimm et al. 2008) and longer growing seasons (Todhunter 1996). Thus, understanding the unique factors that control multiscale spatiotemporal UHI variability for a given city can be critical to urban planning and climate change mitigation efforts.

Despite such extensive study, many aspects of UHIs remain poorly understood since much of the understanding has been derived from the synthesis of multiple case studies conducted over short-term observing periods when optimal weather conditions for intense UHI development were prevalent. As a result, Grimmond (2006) encouraged UHI analysis over a greater range of temporal scales and across all weather conditions so temporal variations in controlling factors can be more fully vetted. Roth (2007) noted a dearth of UHI studies for subtropical cities despite the recent rapid growth in their collective population. Mahmood et al. (2014) argued for more analyses of relationships between UHI intensity and LULC. Finally, both Stewart (2011) and F. Chen et al. (2012) recommended careful site selection and better documentation of site metadata to facilitate meaningful comparisons between cities and with numerical simulations.

In this study, we document the multiscale temporal variability of the Charlotte, North Carolina, UHI using a combination of hourly surface observations from a regional network of weather and air-quality stations over a 5 -yr period, and monthly mean temperatures from two stations over a 40-yr period. Motivation for selecting Charlotte was guided by the shortcomings noted above. First, Charlotte is a subtropical city that has experienced rapid population growth, increased air pollution, and considerable LULC change over the last three decades. Second, recent climate projections (Wuebbles et al. 2014) suggest Charlotte may experience more frequent heat waves and extreme precipitation events, along with less frequent frontal/cyclone passages, over the next century. Last, as far as we know, no detailed analysis of the Charlotte UHI has been reported in the literature. Our specific goals include 1) providing relevant metadata for all observing sites and carefully select the rural reference site, 2) documenting UHI intensity variations over temporal scales ranging from diurnal to interannual, and 3) determining the relative control of various weather and air-quality factors on UHI intensity.

\section{Overview of the study area}

The Charlotte metropolitan region (CMR) encompasses $17700 \mathrm{~km}^{2}$ spread across 14 counties of the Southern Piedmont ecoregion in North and South Carolina (Fig. 1). The rolling landscape ranges in elevation from 50 to $500 \mathrm{~m}$ MSL along a gentle northwest-to-southeast slope. The climate is humid subtropical (Köppen Cfa). Mean temperatures range from $5^{\circ} \mathrm{C}$ in January to $24^{\circ} \mathrm{C}$ in July (Fig. 2). Winters tend to be drier but precipitation is common in all seasons. The mean annual precipitation is $1060 \mathrm{~mm}$. Snowfall is rare (typically 2 days $\mathrm{yr}^{-1}$ ) and often melts within one day. Winds tend to be stronger and northerly in winter and spring when passing cyclones are more intense and cold-air damming events are common, whereas summer and autumn often exhibit weaker southwesterly flow (Fig. 3). Frontal passages are common in all seasons.

During the early and midtwentieth century, the CMR population grew steadily (at a rate consistent with the national average) while the economy transitioned away from agriculture; the percentage of farmland decreased from a high of $70 \%$ in 1949 to a low of $24 \%$ in 1974 as land was reverted to mixed-hardwood and pine forests, and developed land area doubled (Napton et al. 2010). However, over the last 30-40 years, the region has grown more rapidly; the population doubled (increasing from 1.16 million in 1980 to 2.24 million in 2010) and the developed land area quadrupled (increasing from $<750 \mathrm{~km}^{2}$ in 1976 to $>3000 \mathrm{~km}^{2}$ in 2006; Meentemeyer et al. 2013). Such growth rates exceeded their respective national averages, and the CMR ranked as the sixth-fastest-growing metropolitan area during this period.

Despite recent rapid growth, the CMR remains a diverse and productive region that still contains large areas of mixed forest and farmland (Fig. 1). Much of the 


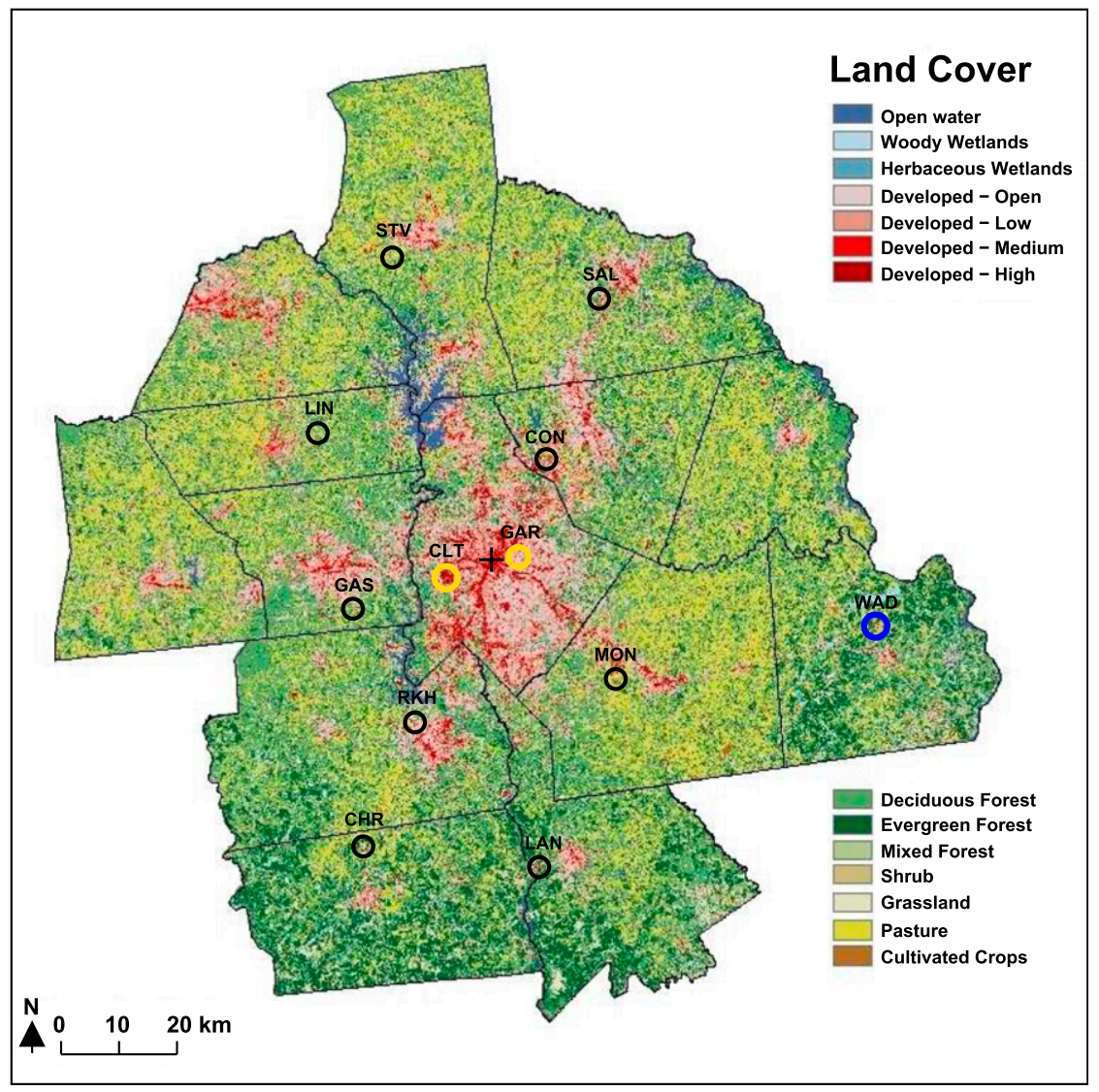

FIG. 1. Surface weather station locations superimposed on the 2011 USGS LULC product across the CMR. The blue circle denotes the rural reference site (WAD), the yellow circles denote the most urbanized sites (GAR and CLT) discussed in this study, and the plus sign denotes the central business district of the urban core. See Table 1 for station metadata and local LULC characteristics.

developed (urbanized) area is centrally located in the city of Charlotte (Mecklenburg County) in the form of mixed high/low-density urban land uses. The central business district consists of compact high-rise commercial and residential buildings with reduced SVFs and limited vegetation. Surrounding the urban core are expansive, open, low-rise suburban neighborhoods with fescue lawns $(20 \%-30 \%$ irrigated) and variable tree cover (scattered mature trees are common in the older neighborhoods near the urban core while few trees are found in the newer fringe neighborhoods). Between 1985 and 2008, rapid suburban expansion resulted in a $60 \%$ increase in impervious surface area coupled with a $36 \%$ reduction in tree cover across Mecklenburg County (Singh et al. 2012).

\section{Data and methods}

\section{a. Site descriptions}

The primary data used in this study were collected by 12 automated surface weather and air-quality stations spread across the region: four are ASOS stations located at the Charlotte (CLT), Gastonia (GAS), Monroe (MON), and Rock Hill (RKH) airports; seven are AWOS stations located at county airports near the towns of Chester (CHR), Concord (CON), Lancaster (LAN), Lincolnton (LIN), Salisbury (SAL), Statesville, (STV), and Wadesboro (WAD); and one is an EPA monitoring site operated by Mecklenburg County Air Quality (MCAQ) at Garinger High School (GAR) near the urban core. Each site was visited to assess local horizon, LULC, building geometry, traffic flow, and any obstructions. Most airport weather stations are sited in secure, open, grassy fields more than $100 \mathrm{~m}$ from runways, roadways, low-rise buildings, and tall obstructions. ${ }^{1}$ The GAR air-quality site was

\footnotetext{
${ }^{1}$ Exceptions included CHR (located $24 \mathrm{~m}$ south of a low-rise hangar adjacent to a concrete tarmac), GAS (located $65 \mathrm{~m}$ east of a sparsely built neighborhood), and SAL (located $60 \mathrm{~m}$ south of a tree stand with tops near $20 \mathrm{~m}$ ).
} 


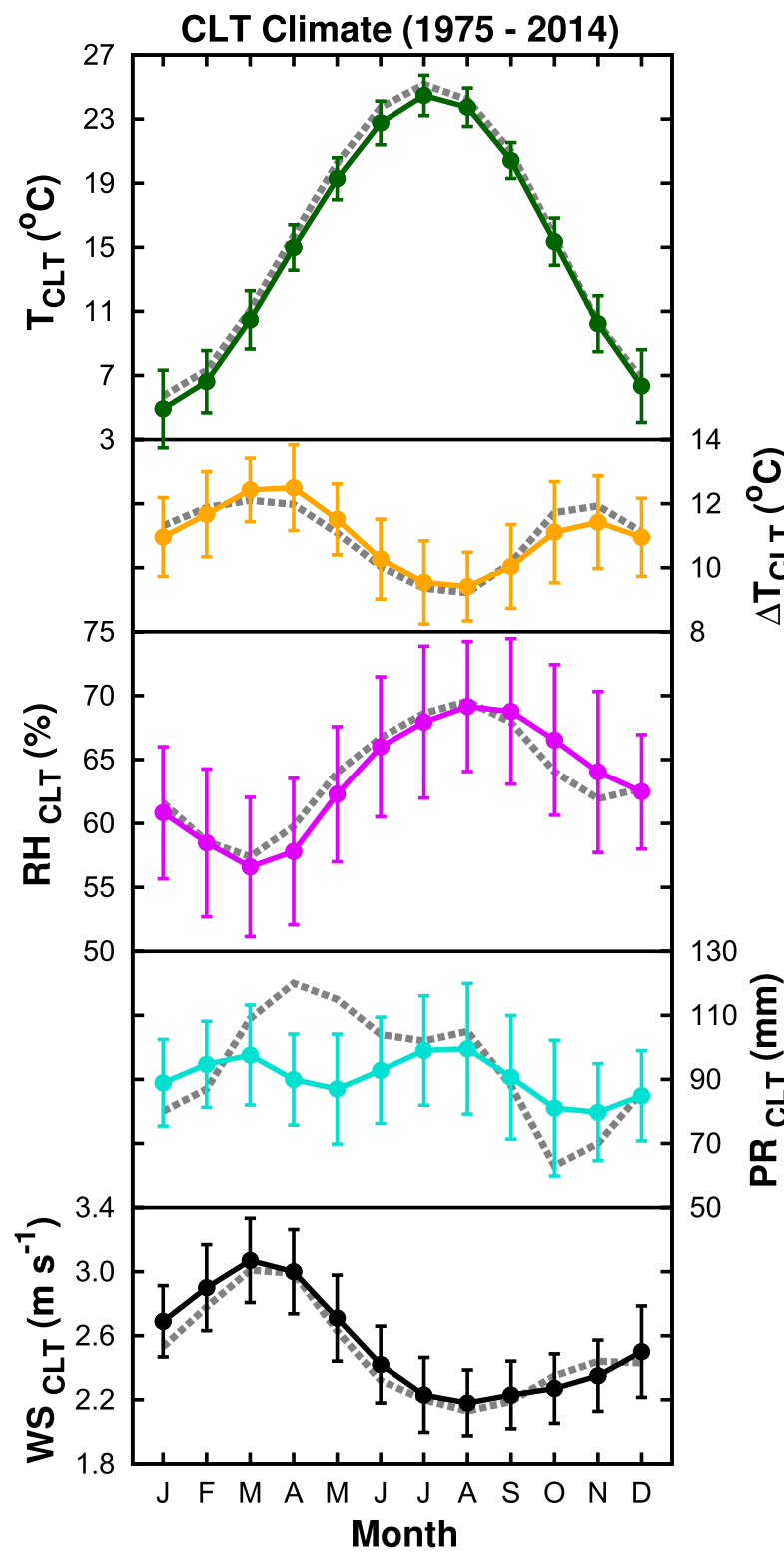

FIG. 2. Climatological monthly means (circles) and standard deviations (error bars) in mean temperature ( $T_{\mathrm{CLT}}$; dark green), daily temperature range ( $\Delta T_{\mathrm{CLT}}$; orange), mean relative humidity $\left(\mathrm{RH}_{\mathrm{CLT}}\right.$; purple), total precipitation $\left(\mathrm{PR}_{\mathrm{CLT}}\right.$; cyan),

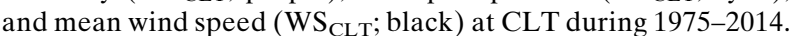
Also shown are monthly means computed for all good dates during the June 2010-May 2015 intensive study period (gray dashed).

located inside a secure fence among open, grassy, recreational fields on school grounds; low-rise residential neighborhoods with scattered trees (tops near $15 \mathrm{~m}$ ) were located $\sim 80 \mathrm{~m}$ to the west and south.

Secondary sources were used to quantify additional site characteristics (see Table 1). Percentages of LULC

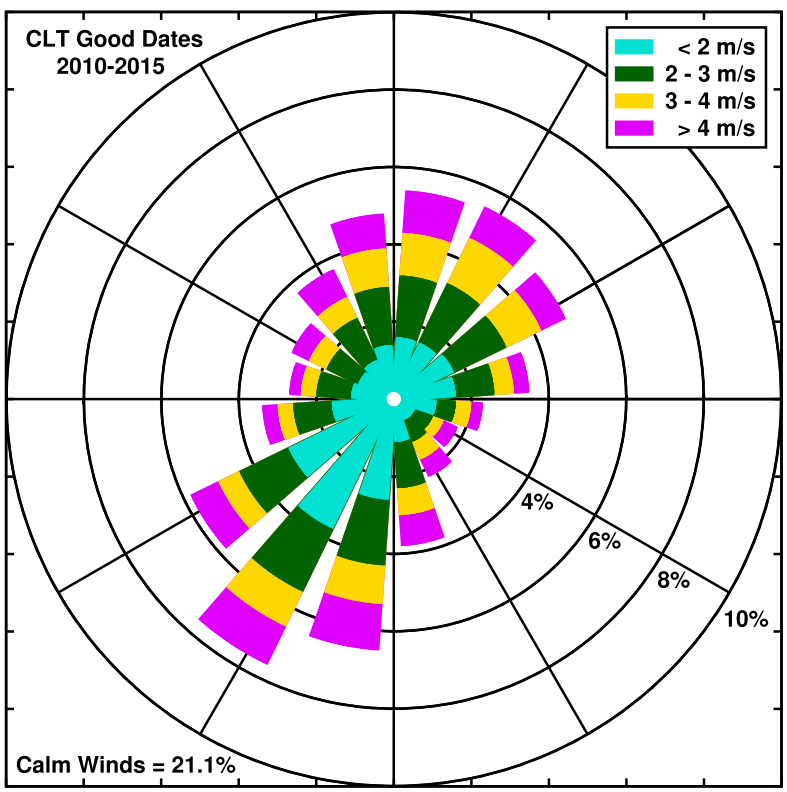

FIG. 3. Wind rose of hourly observations at CLT for all good dates between June 2010 and May 2015.

types within a $1.5-\mathrm{km}$ radius $^{2}$ of each station were determined from the 2011 National Land Cover Database (30-m resolution; Jin et al. 2013). For simplicity, the 14 LULC types found across the CMR (Fig. 1) were grouped into four broad classes: developed (open, low, medium, and high), farmland (shrub, grassland, pasture, and crops), forest (deciduous, evergreen, and mixed), and water (open and wetlands). Topographic relief was defined as the difference between station elevation and the mean elevation within a $1.5-\mathrm{km}$ radius on a $3-\mathrm{m}$ resolution USGS digital elevation model (Schatz and Kucharik 2014). Local SVFs were computed from USGS aerial lidar observations within a 500-m radius using the L. Chen et al. (2012) methods. Finally, each site was assigned a local climate zone (LCZ) classification based on the LULC characteristics and site-visit metadata following Stewart and Oke (2012).

\section{b. Site classification}

Canopy-layer estimates of UHI intensity and spatiotemporal variability often require classification of the surface observation sites into somewhat arbitrary categories (e.g., urban, suburban, and rural) based on

\footnotetext{
${ }^{2}$ Previous studies (e.g., Lindén et al. 2015) found the most representative thermal source area influencing temperatures at canopy-layer weather stations to be within $1000 \mathrm{~m}$ or less, depending on surface geometry, LULC, season, weather conditions, and prevailing wind direction. Here, a common 1500-m radius was used to account for all such dependencies at multiple sites.
} 


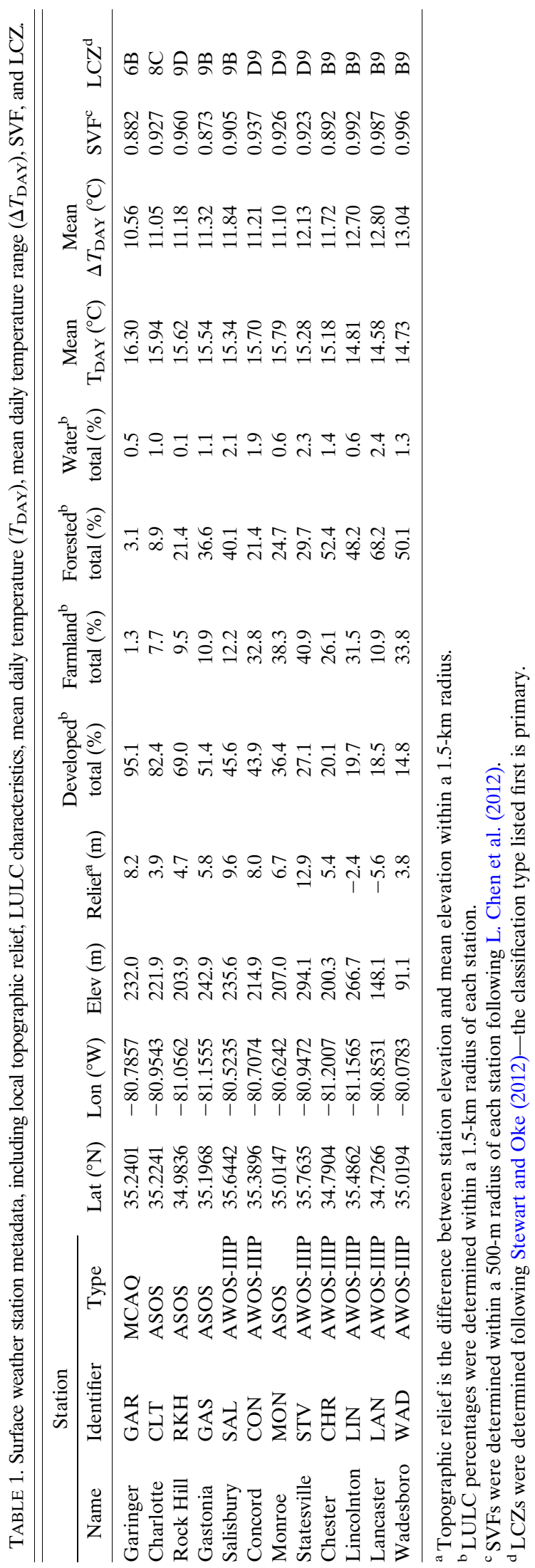

metrics of human modification to the surrounding natural landscape. The least modified site is often selected as the rural reference. While this general methodology has known flaws (Lowry 1977; Stewart and Oke 2012), it remains the optimal choice when limited spatiotemporal observations are available. As such, a number of metrics have been used to identify "optimal" rural reference sites, including prevailing wind direction (Huff and Changnon 1973), the smallest local population (Karl et al. 1988), population density (Jones et al. 1999), or nightlight intensity (Peterson 2003), the greatest local vegetation coverage (Gallo and Owen 1999), the least local coverage of developed land (Lindén et al. 2015), the greatest distance from the urban core (Ren et al. 2015) and/or large water bodies (Sakakibara and Owa 2005), and the greatest diurnal temperature range $\left(\Delta T_{\mathrm{DAY}}\right.$; Brown and DeGaetano 2010).

All CMR site characteristics are listed in Table 1. The least developed (or most rural) sites are CHR, LAN, LIN, and WAD; each is located $>40 \mathrm{~km}$ from the urban core, surrounded by open farmland and scattered trees in a manner broadly consistent with the land-cover characteristics for the entire CMR (18\% developed, $32 \%$ farmland, $47 \%$ forested, and 3\% water). Of these, WAD exhibits the most optimal characteristics for a rural reference; the site is in an open, level, grassy field away from airport infrastructure, is furthest from the urban core with the smallest local population total, density, and change (since 1970), exhibits the largest mean $\Delta \mathbf{T}_{\mathrm{DAY}}$, and is rarely influenced by downwind advection of any urban plume (Figs. 1 and 3). In contrast, the most developed (urbanized) sites are GAR and CLT; both are located $<10 \mathrm{~km}$ of the urban core, and surrounded by considerable built infrastructure. However, neither site is located within the central business district where a UHI maximum might be expected as a result of a combination of compact high-rise buildings with high heat capacities, deep street canyons with reduced SVFs, and limited vegetation (e.g., Oke et al. 1991; Unger 1996). Nevertheless, both sites exhibit the smallest mean $\Delta T_{\mathrm{DAY}}$ and are often located downwind of the urban core. Thus, hereinafter, both GAR and CLT are considered "urban" sites, WAD will be used as the "rural" reference, and all remaining sites are broadly classified as "suburban."

\section{c. Meteorological observations}

To assess daily, intra-weekly, monthly, and seasonal UHI variability, all available hourly observations of station pressure $(P)$, temperature $(T)$, relative humidity $(\mathrm{RH})$, precipitation (PR), wind speed (WS), wind direction (WD), cloud cover (CLC), cloud base (CLB), and net solar radiation (SR) at each CMR site were 
obtained from the NCDC and MCAQ for the 5-yr period between June 2010 and May 2015. Detailed information on station configuration, sensors, and data quality control is available at the NCDC (now the NCEI; http://www.ncdc.noaa.gov/) and MCAQ (https:// www.mecknc.gov/LUESA/AirQuality/Pages/default.aspx) websites. All nominal CLC observations were converted to octal equivalents $(\mathrm{CLR}=0 ; \mathrm{SCT}=2.5 ; \mathrm{BKN}=6 ; \mathrm{OVC}=8)$ and unreported CLBs (for CLR and SCT skies) were assigned an altitude of $10 \mathrm{~km}$. The CLBs at CLT were observer augmented with cloud layers up to $10 \mathrm{~km}$; CLBs at all other sites were confined to altitudes at or below $3 \mathrm{~km}$ (the ceilometer's maximum range). The quantity SR was only observed at the GAR site (in place of CLC and CLB).

Accurate UHI analysis from multiple surface stations requires adjustments for differences in station elevation, latitude, local relief, and observing practices, as well as changes in station location and instrumentation (Winkler et al. 1981; Peterson 2003; Lindén et al. 2015). During our 5 -yr study period, all locations, instrumentation, and data acquisition procedures were constant, but differences in site elevation (ranging from 91 to $294 \mathrm{~m}$; see Table 1) and latitude $\left(34^{\circ}-36^{\circ} \mathrm{N}\right)$ could introduce site-to-site temperature differences as large as $1.5^{\circ} \mathrm{C}$. Since regular regional soundings are unavailable, all hourly surface temperatures were adjusted to a common elevation $(229 \mathrm{~m}$ of the CMR urban core) using the dry-adiabatic lapse rate $\left(-9.8^{\circ} \mathrm{Ckm}^{-1}\right)$; a conservative choice (which may underestimate nocturnal UHI intensities) given typical diurnal variations in boundary layer lapse rates (Godowitch et al. 1985). For differences in station latitude (i.e., differences in background climate due to insolation), hourly temperatures were adjusted to a common central latitude of $35.23^{\circ} \mathrm{N}$ using $-0.9^{\circ} \mathrm{C}$ per degree of latitude following Peterson (2003). No adjustments for differences in local relief (e.g., cold-air drainage) were attempted.

Estimates of urban heat island intensity (UHII) were determined by subtracting the adjusted temperature at a station from the corresponding adjusted temperature at the WAD site:

$$
\mathrm{UHII}=T_{\mathrm{Xxx}}-T_{\mathrm{wAD}},
$$

where the XXX subscript is a generic three-letter station identifier for any urban or suburban site.

Several additional data sources and computed parameters were used to characterize meteorological conditions across the region. First, to determine if precipitation occurred anywhere within the CMR on a given date, the Advanced Hydrological Prediction Service multisensor daily precipitation archive (http://water. weather.gov/precip/index.php) was consulted. Dates with no reported surface or radar-based precipitation across the
CMR were deemed free of precipitation. Second, to determine the existence-passage of any fronts, surface weather charts in the Unisys archive (http://weather.unisys. com/archive/sfc_map/) were consulted. Dates without an analyzed front passing within $100 \mathrm{~km}$ of the CMR were deemed free of frontal passages. Third, the often-used weather factor (WXF; Runnalls and Oke 2000) that combines surface winds with cloud cover and cloud type was computed via

$$
\mathrm{WXF}=\mathrm{WS}^{-0.5}\left(1-k n^{2}\right),
$$

where $k$ is a nondimensional coefficient that accounts for decreasing cloud temperature with height and $n$ is the cloud-cover fraction. Determination of $k$ requires unavailable hourly information on cloud type, depth, and optical thickness (Morgan et al. 1971). Thus, the $k$ values used by Runnalls and Oke (2000) for low (0.88), medium (0.73), and high (0.24) clouds were assigned CLB heights of 2,5 , and $8 \mathrm{~km}$, respectively. Hourly estimates of $k$ were then computed through linear interpolation using the observed CLB and assuming $k=1$ at the surface and $k=0$ for either clear skies or cloud bases above $10 \mathrm{~km}$. WXFs range from 0 (for overcast and/or windy conditions) to 1 for (clear and calm conditions). Fourth, to distinguish stable from unstable conditions, an hourly Pasquill-Gifford-Turner stability index (STB; Turner 1964) was computed at each site (except for GAR). The scheme uses WS, CLC, and solar altitude to classify atmospheric stability into one of seven categories: 1) extremely unstable, 2) unstable, 3) slightly unstable, 4) neutral, 5) slightly stable, 6) stable, and 7) extremely stable. Moreover, the nondimensional index can be easily computed from standard surface observations, and compares well to more sophisticated stability estimates (Mohan and Siddiqui 1998).

Next, hourly observations on each date were screened for missing data. Only dates with no missing $P, T$, RH, WS, $\mathrm{WD}, \mathrm{CLC}, \mathrm{CLB}$, or SR at all 12 sites between sunrise and the next day's sunset ( $\sim 36 \mathrm{~h}$ or day-night-day) were used. These criteria were adopted to ensure a common dataset that could be used for multiscale temporal analyses without introducing biases from site-to-site variations in sample size. Such restrictions removed 267 dates (or $\sim 15 \%$ of the 5 -yr period), leaving 1558 dates with complete hourly time series.

To facilitate comparisons with previous studies, two sets of dates were used for our intra-annual UHI analyses. The first set comprises all 1558 dates with no missing data ("good" dates). The second comprises a subset of 404 good dates when weather conditions were ideal for development of an intense UHI ("optimal" dates). In this study, an optimal date exhibited clearscattered skies (mean CLC $<4$ oktas), light winds 
(mean WS $<2.0 \mathrm{~m} \mathrm{~s}^{-1}$ ), and low humidity (mean $\mathrm{RH}<$ $80 \%$ ) across the region with no precipitation or frontal passages. Such criteria are broadly consistent with prior descriptions or definitions of ideal UHI conditions (Runnalls and Oke 2000; Gedzelman et al. 2003; Fortuniak et al. 2006; Holmer et al. 2013).

Finally, to assess interannual UHII trends, all available monthly mean temperatures at CLT and WAD for the 115-yr period between 1900 and 2014 were obtained from the Global Historical Climatology Network (GHCN) database available through GISS (http://data.giss.nasa.gov/ gistemp/station_data/), whereby the time series have been adjusted for standard inhomogeneities (changes in station location, instrumentation, and time of observation) but not for urbanization (Hansen et al. 2001). Continuous observations for WAD were limited to the 40-yr period between 1975 and 2014. First, annual means were computed from the monthly data for each station, and then adjusted for elevation and latitude using the same methods discussed above. Next, UHIIs were computed from the annual time series, and linear trends were calculated via the standard least squares method. Note that the annual means comprise all dates and weather conditions.

\section{d. Air-quality observations}

To contextualize intra-weekly UHI variability in relation to atmospheric emissions generated by those economic sectors most linked to a standard workweek (i.e., transportation and energy), all available air-quality observations at GAR were obtained from MCAQ during the same 5-yr period. Our analysis was restricted to the pollutants monitored hourly or daily: ozone $\left(\mathrm{O}_{3}\right)$, carbon monoxide $(\mathrm{CO})$, nitrogen dioxide $\left(\mathrm{NO}_{2}\right)$, sulfur dioxide $\left(\mathrm{SO}_{2}\right)$, and particulate matter less than 2.5 or $10 \mu \mathrm{m}$ in diameter $\left(\mathrm{PM}_{2.5}\right.$ and $\mathrm{PM}_{10}$ ). Detailed information on all observed pollutants, sensors, and data quality control is available at the MCAQ website (see above).

\section{e. Statistical methods}

Various nonparametric statistics were used to identify significant trends, correlations, and differences in means. The Mann-Kendall trend test was applied to identify significant linear trends; no time series prewhitening or block bootstrapping was required since no significant serial correlation was detected via partial and autocorrelation analysis. Significant correlations among weather parameters at a site or for the same parameter at different sites were evaluated using Spearman correlation. Last, the Wilcoxon Mann-Whitney test was used to distinguish differences in means between two sites. All statistical tests were conducted using the JMP-12.0 software and a two-tailed significance level of $p<0.05$ (or the $95 \%$ confidence level).

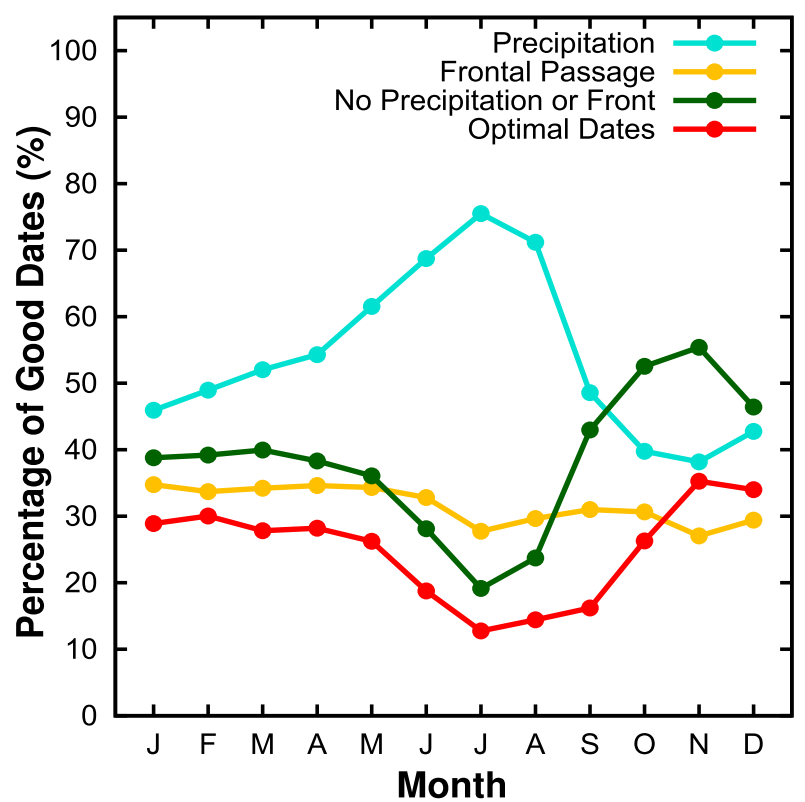

FIG. 4. Monthly percentage of good dates with rainfall observed within the CMR (cyan), with a frontal passage through the CMR (orange), with neither rainfall nor a frontal passage observed in the CMR (dark green), and classified as an optimal date (red). See the text for definitions.

\section{f. Data representativeness}

An ideal database for canopy-layer UHI analysis would include multiple observing stations spread across representative percentages of the regional LULC and SVF spectra with similar local relief, open exposures, and no missing data throughout a multiyear period. The available database is less than ideal, but sufficient for the goals addressed here. Particularly, the 5-yr sample of good dates was evenly distributed across all months, ranging from a maximum of $152(\sim 99 \%$ of all dates) in December to a minimum of $118(\sim 76 \%)$ in August. Moreover, the weather observed on good dates was representative of the long-term climate (see Figs. 2 and 3), including the percentage of dates with frontal passages and/or precipitation (Fig. 4); the exception was wetter-than-normal conditions in spring. Optimal dates were also distributed across all months, ranging from a maximum of 53 ( $\sim 36 \%$ of good dates) in November when daily precipitation was infrequent to a minimum of $16(\sim 13 \%)$ July when precipitation was common.

Our greatest concern was the impact of intraregional variations in cloud cover, winds, humidity, and stability on hourly UHI intensity. Several methods for estimating representative regional conditions were explored, including various multistation weighted means. However, because of multiple confounding issues among suburban sites, a simple hourly average of the CLT and WAD 
TABLE 2. Average nocturnal means and cross-site correlation coefficients for UHI intensity and select weather parameters on all good dates at the two most urbanized sites (GAR and CLT) and the rural reference site (WAD). Boldface coefficients denote statistical significance at the $5 \%$ level. See the text for parameter and subscript definitions.

\begin{tabular}{|c|c|c|c|c|c|c|c|}
\hline \multirow[b]{2}{*}{ Parameter } & \multirow[b]{2}{*}{ Units } & \multicolumn{3}{|c|}{ Avg of all good dates } & \multicolumn{3}{|c|}{ Correlation coef } \\
\hline & & GAR & CLT & WAD & GAR-CLT & CLT-WAD & GAR-WAD \\
\hline $\mathrm{UHII}_{\mathrm{XXX}-\mathrm{NOCT}}$ & ${ }^{\circ} \mathrm{C}$ & 2.24 & 1.72 & - & 0.92 & - & - \\
\hline $\mathrm{RH}_{\mathrm{XXX} \text {-NOCT }}$ & $\%$ & 72.7 & 75.0 & 80.9 & 0.72 & 0.69 & 0.62 \\
\hline $\mathrm{WS}_{\mathrm{XXX} \text { XOCT }}$ & $\mathrm{ms} \mathrm{s}^{-1}$ & 2.1 & 2.3 & 1.9 & 0.75 & 0.77 & 0.71 \\
\hline CLC $_{\text {XXX-NOCT }}$ & oktas & - & 4.2 & 2.6 & - & 0.69 & - \\
\hline CLB $_{\text {XXX-NOCT }}$ & $\mathrm{m}$ & - & 6610 & 7220 & - & 0.82 & - \\
\hline $\mathrm{WXF}_{\mathrm{XXX}-\mathrm{NOCT}}$ & - & - & 0.5 & 0.6 & - & 0.78 & - \\
\hline STB $_{X X X-N O C T}$ & - & - & 5.4 & 6.0 & - & 0.74 & - \\
\hline
\end{tabular}

observations was adopted to represent the regional mean conditions. Despite $\sim 80 \mathrm{~km}$ between CLT and WAD, the statistically significant correlations among their nocturnal mean RH, WS, CLC, CLB, WXF, and STB on good dates (Table 2) suggests a simple mean will capture regional variability well.

Secondary concerns include the unavoidable lack of a weather station within the traditional urban core and the use of only one rural site as reference. Based on a survey of UHI analyses conducted via mobile transects, intraurban temperature variations are typically $<2^{\circ} \mathrm{C}$ if observations in and near large urban parks are neglected (e.g., Unger et al. 2001; Hart and Sailor 2009; Brandsma and Wolters 2012). Likewise, the impact of rural variability on UHIIs is $<2^{\circ} \mathrm{C}$ when LULC characteristics near the chosen reference site and across the greater region are similar (e.g., Hawkins et al. 2004; Ren et al. 2015). Thus, our analysis should provide reasonable, but conservative, estimates for the maximum UHI intensity.

\section{Results and discussion}

Our statistical analysis of the Charlotte UHI addresses multiple temporal scales (hourly, daily, intra-weekly, monthly-seasonal, and interannual) using weather and air-quality parameters derived from individual or combined sites. Thus, for clarity, a naming convention was adopted whereby each parameter is assigned two subscripts: the first identifies the source station(s) and the second denotes any temporal averaging. The station subscripts list either a specific station (see Table 1), a generic station (XXX; applicable to multiple stations within a given table/figure), or a regional average (AVG; simple average computed from the CLT and WAD observations). The temporal subscripts denote either hourly (HOUR) observations, a daytime mean (DAY) between $1 \mathrm{~h}$ after sunrise and $1 \mathrm{~h}$ before sunset, a nocturnal mean (NOCT) between $1 \mathrm{~h}$ after sunset and $1 \mathrm{~h}$ before sunrise, a daily maximum (MAX) observed between one hour after sunrise and one hour before the next sunrise, an annual mean (ANNUAL), or a generic period (YYY; applicable to multiple averaging periods within a given table-figure). For example, STB $_{\text {AVG-NOCT }}$ is the nocturnal mean stability for the region on a given date, and $\mathrm{UHII}_{\mathrm{GAR}-\mathrm{NOCT}}$ is the nocturnal mean UHI intensity at GAR on a given date. Such naming convection is used in all tables, figures, and throughout the remainder of the paper.

\section{a. Overall UHI magnitudes}

As a first step, the overall average daytime and nocturnal mean UHII were computed for all good dates at each urban and suburban site (Table 3). GAR and CLT exhibited the largest mean heat islands, with $\mathrm{UHII}_{\mathrm{XXX} \text {-DAY }}$ and $\mathrm{UHII}_{\mathrm{XXX}-\mathrm{NOCT}}$ often exceeding $0.6^{\circ}$ and $1.7^{\circ} \mathrm{C}$, respectively, supporting their classification as urban despite being just outside the urban core. The surrounding suburban sites exhibited relatively smaller UHIIs that roughly correlated with the local percentage of developed land (see Table 1). Such overall values were small relative to

TABLE 3. Average daytime mean and nocturnal mean UHI intensity for all good dates at each listed CMR station relative to the rural reference station (WAD). Standard deviations $(\sigma)$ are also provided. See the text for parameter and subscript definitions.

\begin{tabular}{|c|c|c|c|c|}
\hline \multirow[b]{2}{*}{ Station } & \multicolumn{2}{|c|}{ Daytime } & \multicolumn{2}{|c|}{ Nocturnal } \\
\hline & UHII XXX-DAY & $\sigma$ & UHII XXX-NOCT & $\sigma$ \\
\hline GAR & 0.69 & 1.10 & 2.24 & 1.86 \\
\hline CLT & 0.62 & 1.11 & 1.72 & 1.97 \\
\hline RKH & 0.48 & 1.33 & 1.23 & 1.91 \\
\hline GAS & 0.43 & 1.28 & 1.11 & 1.93 \\
\hline SAL & 0.25 & 1.22 & 0.89 & 1.72 \\
\hline $\mathrm{CON}$ & 0.37 & 1.50 & 1.43 & 1.95 \\
\hline MON & 0.50 & 1.08 & 1.52 & 1.62 \\
\hline STV & 0.40 & 1.20 & 1.52 & 1.60 \\
\hline CHR & 0.26 & 1.06 & 0.58 & 1.64 \\
\hline LIN & 0.08 & 1.23 & 0.18 & 1.67 \\
\hline LAN & -0.02 & 1.05 & -0.30 & 1.42 \\
\hline
\end{tabular}




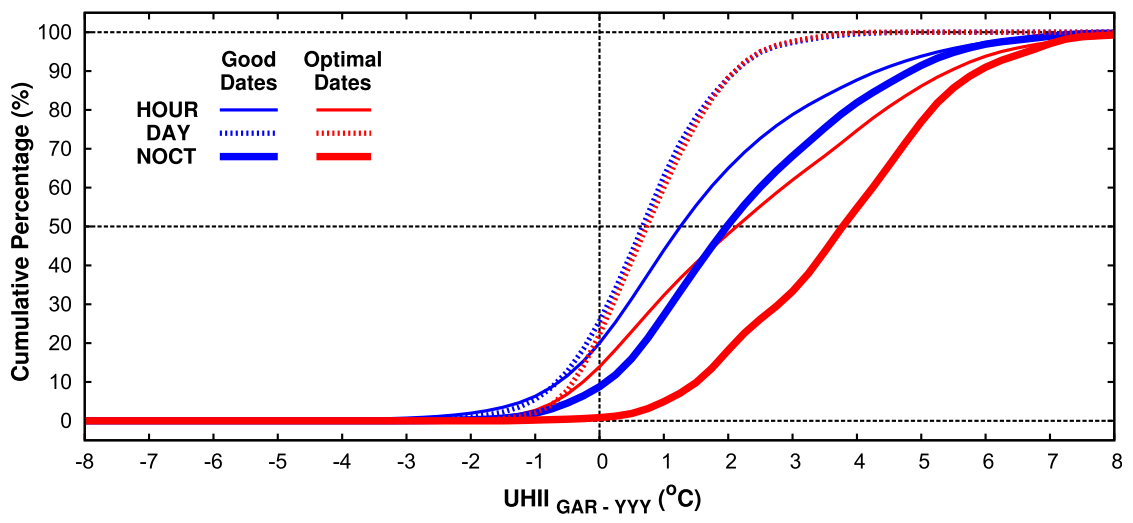

FIG. 5. Cumulative percentage of hourly, daytime mean, and nocturnal mean UHI intensity at GAR for all good and optimal dates between June 2010 and May 2015. See the text for parameter and subscript definitions.

typical UHIIs reported for similar-sized cities; however, the averages included all weather conditions on all good dates. As will be shown below, consistent with the large overall standard deviations (Table 3), day-to-day UHI intensity is strongly dependent on weather variability.

GAR exhibited the largest UHIIs among all sites. Figure 5 shows the cumulative frequency distributions of the $\mathrm{UHII}_{\mathrm{GAR}-H O U R}, \mathrm{UHII}_{\mathrm{GAR}-\mathrm{DAY}}$, and $\mathrm{UHII}_{\mathrm{GAR}-\mathrm{NOCT}}$ for good and optimal dates. Over $80 \%$ of hourly observations exhibited a UHI signature, with $\sim 35 \%$ of daytime means and $\sim 70 \%$ of nocturnal means greater than $1^{\circ} \mathrm{C}$. The most intense heat islands clearly occurred at night, as $\mathrm{UHII}_{\mathrm{GAR}-\mathrm{NOCT}}$ exceeded $4^{\circ} \mathrm{C}$ on $\sim 20 \%$ of good dates and $\sim 50 \%$ of optimal dates. The largest $\mathrm{UHII}_{\text {GAR-HOUR }}\left(9.5^{\circ} \mathrm{C}\right)$ and $\mathrm{UHII}_{\text {GAR-NOCT }}\left(8.9^{\circ} \mathrm{C}\right)$ were observed on the night of 23/24 April 2011 under clear, calm, dry, and stable conditions with a strong anticyclone overhead. The largest $\mathrm{UHII}_{\mathrm{GAR}-\mathrm{DAY}}\left(4.6^{\circ} \mathrm{C}\right)$ occurred on 1 July 2012 in relation to convective storms moving through the region. Cumulative distributions for other stations were similar (not shown).

\section{b. Hourly-diurnal variability}

Numerous case studies have collectively documented the UHI diurnal cycle across a spectrum of cities. Consensus reveals that nocturnal UHIs are more common and intense than daytime UHIs because of greater cooling at rural sites relative to urban sites. However, consensus has not been reached as to when the nocturnal UHI maximum occurs (estimates range from sunset to sunrise) or when the urban/rural cooling maxima occur (estimates range from $2 \mathrm{~h}$ before sunset to $4 \mathrm{~h}$ after sunset). Such variability has been attributed to climate (Roth 2007), season (Chow and Roth 2006), local weather (Tumanov et al. 1999), geography (Acero et al. 2013), LULC distributions (Chow and Svoma
2011), urban SVFs (Upmanis et al. 1998), anthropogenic heating (Jauregui 1997), or various combinations of such controls (Giovannini et al. 2011; Holmer et al. 2013) often unique to each city. Here, we focus on the diurnal cycle at GAR (where the most intense UHIs were observed) for both good and optimal dates. To further facilitate comparison, we normalized the diurnal cycle following Runnalls and Oke (2000), whereby the 24-h day is scaled from 0 to 2 , with 0.5 and 1.5 corresponding to the daily times of sunset and sunrise, respectively.

Figure 6a shows the hourly evolution of UHI intensity on good dates. In the afternoon, UHII $_{\text {GAR-HOUR were }}$ often confined within $\pm 1^{\circ} \mathrm{C}$, but prominent daytime heat islands (and cool islands) were observed. Rapid growth in the nocturnal UHI typically began $2-3 \mathrm{~h}$ before sunset and continued until 3-4h after sunset. Next, the UHI exhibited either slow growth or remained constant until sunrise, followed by a steady decline between sunrise and midday. The mean UHI maximum on good dates occurred at sunrise. The hourly UHI evolution on optimal dates (Fig. 7a) was similar but with two notable exceptions; prominent afternoon heat islands and cool islands were less common, and the mean $\mathrm{UHII}_{\mathrm{GAR} \text {-HOUR }}$ maximum occurred $1-2 \mathrm{~h}$ before midnight. Such diurnal evolution is consistent with prior UHIs observed in the humid-subtropical (Cfa) climate without coastal or topographic modulation (e.g., Basara et al. 2008).

Figures $6 \mathrm{~b}$ and $7 \mathrm{~b}$ show the frequency of diurnal UHI maxima for good and optimal dates, respectively. Overall, UHI maxima were most often observed $\pm 2 \mathrm{~h}$ of sunrise, but significant secondary peaks were present each season between sunset and midnight. While the sunrise UHI maximum can be explained via greater net nocturnal cooling at the rural site, the earlier UHI maxima result from a variety of seasonal processes. First, the summer (JJA) peak observed near sunset on 


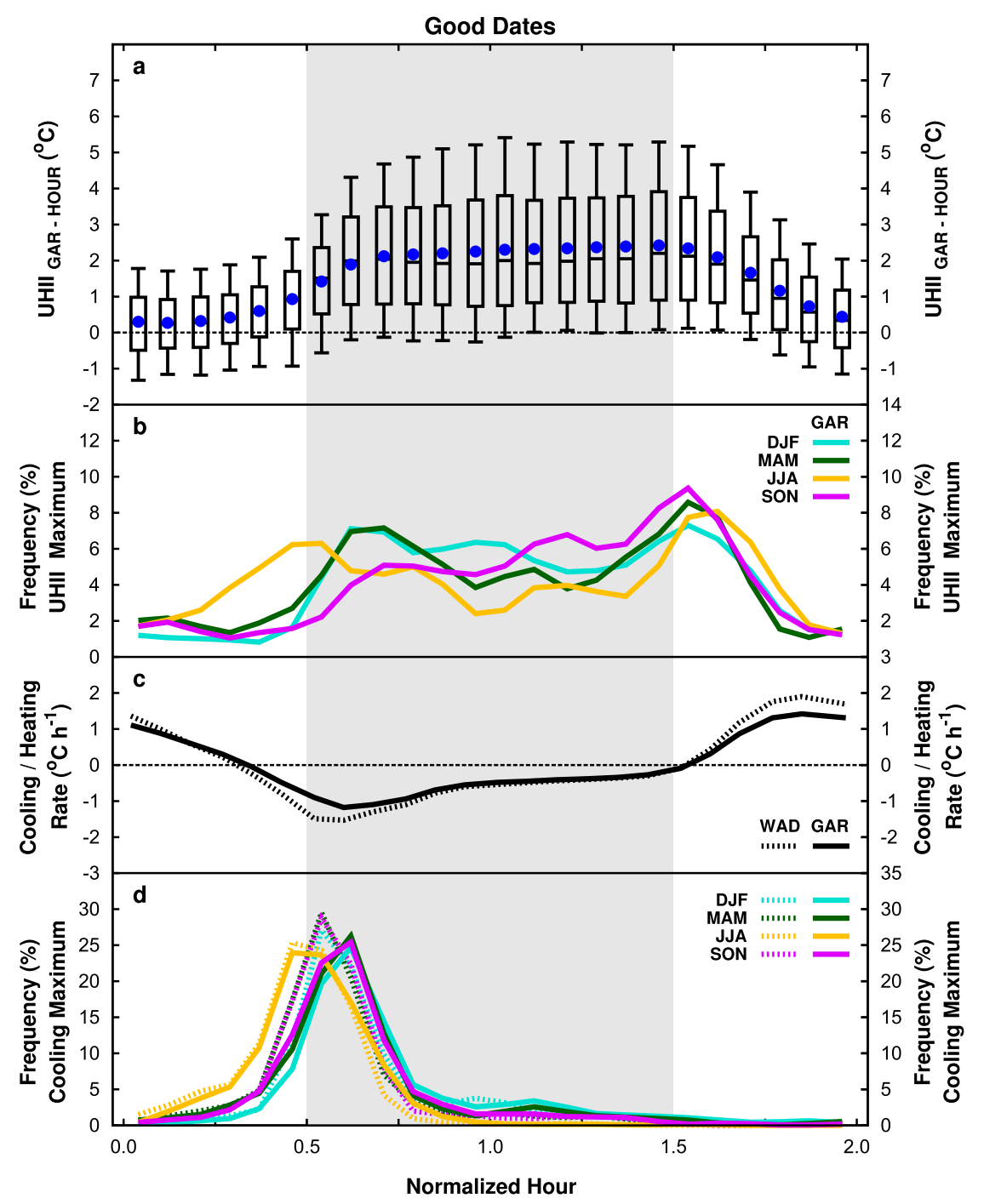

FIG. 6. (a) Box-and-whisker plots of hourly UHI intensity at GAR in all seasons, (b) frequency of the diurnal maximum UHI intensity at GAR for each season, (c) mean hourly cooling/heating rate at GAR and WAD in all seasons, and (d) frequency of the diurnal maximum cooling rate at GAR and WAD in each season for all good dates as a function of normalized hour. In (a) and subsequent figures, the box center and ends denote the median (50\%), first quartile (25\%), and third quartile (75\%), respectively, while the whiskers denote the $10 \%$ and $90 \%$ values; the hourly means (blue circles) are also shown. See the text for parameter, subscript, and normalization definitions.

good dates (but not optimal dates) likely resulted from afternoon/evening precipitation common during the warm season (Figs. 2 and 4). Such events (a portion of which may have been initiated/enhanced by a prominent afternoon UHI; Dixon and Mote 2003) often induce significant urban cooling (via cold convective downdrafts and surface evaporation) that precludes nocturnal UHI development. The lack of a similar peak on optimal dates (defined as precipitation free) is consistent. Second, the winter (DJF) peak observed
2-4 h after sunset likely resulted from two processes; early-evening anthropogenic heat release from heated buildings and vehicular traffic (Sailor and Lu 2004), and rural dewfall with less (or no) urban dewfall (Holmer and Eliasson 1999). Such processes are more prominent in winter when regional conditions are colder/drier and sunsets are earlier. Again, the weaker early-evening peaks observed on optimal dates in spring (MAM) and autumn (SON), but not summer, are consistent. 


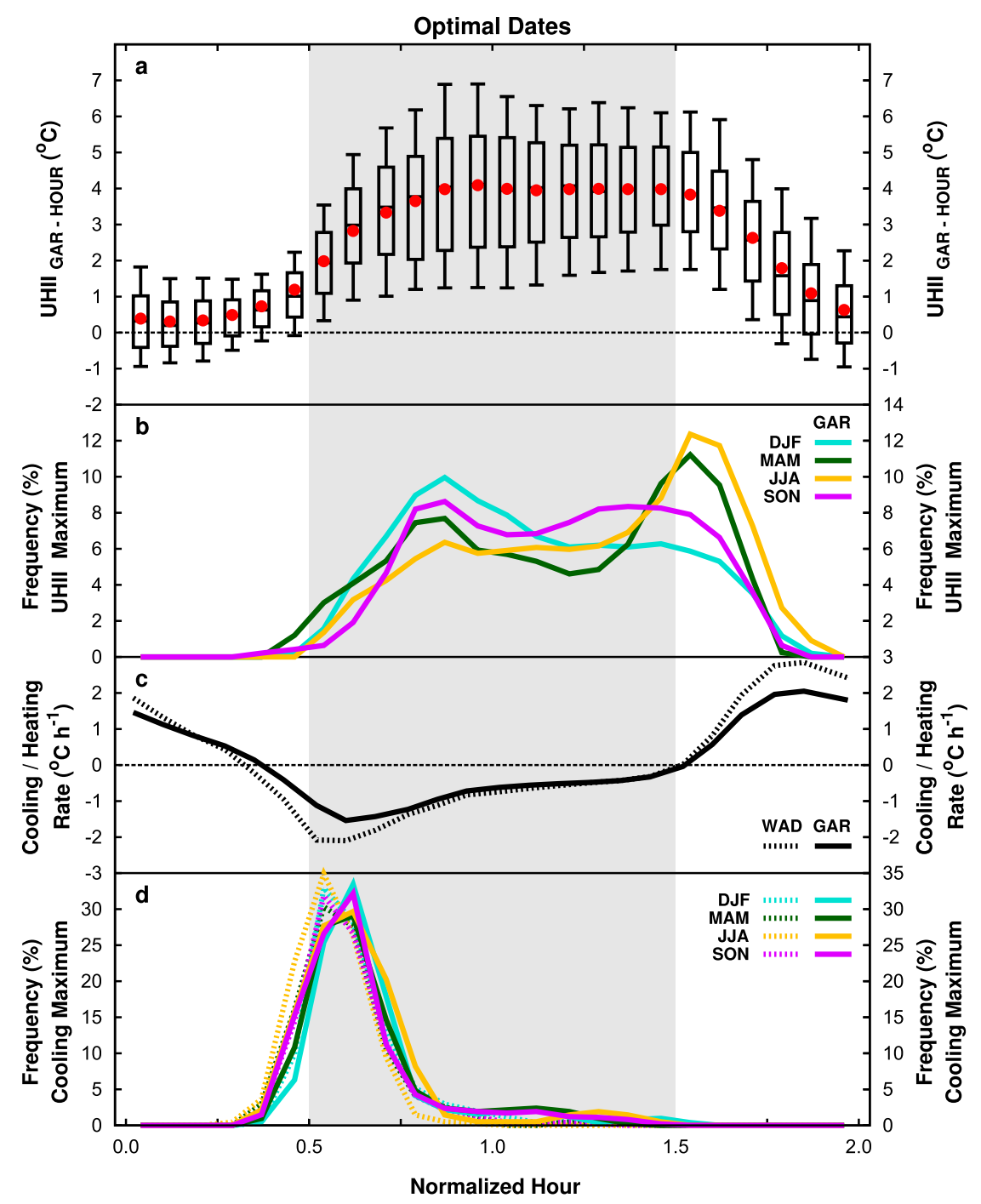

FIG. 7. As in Fig. 6, but for optimal dates.

The mean hourly cooling/heating rates for good and optimal dates (Figs. 6c and 7c) exhibit the classic twophase nocturnal cooling described by Holmer et al. (2013) whereby the early phase (from sunset to midnight) is characterized by large dissimilar cooling rates, and the late phase (midnight to sunrise) exhibits smaller similar rates. On good dates, the onset of rural cooling (at WAD) began 3-4h before sunset and reached a mean maximum $\left(-1.6^{\circ} \mathrm{Ch}^{-1}\right) 1-2 \mathrm{~h}$ after sunset, whereas urban cooling (at GAR) lagged by $1-2 \mathrm{~h}$ and attained a weaker mean maximum $\left(-1.2^{\circ} \mathrm{Ch}^{-1}\right)$. Then, despite significant rate reductions before midnight, weak cooling persisted at both sites until sunrise. Daytime heating maxima often occurred 3-4 h after sunrise. Optimal dates exhibited similar evolution but mean maxima were $25 \%-45 \%$ larger. When stratified by season (Table 4), the largest maximum cooling (heating) rates occurred in autumn (summer), but the greatest urban-rural differences in both maximum cooling and heating occurred in the winter. Such maximum rates are consistent with values reported for cities in humid and/ or subtropical climates (Runnalls and Oke 2000; Chow and Roth 2006; Holmer et al. 2013).

Figures $6 \mathrm{~d}$ and $7 \mathrm{~d}$ show the frequency of diurnal cooling maxima for good and optimal dates, respectively. Over $90 \%$ of cooling maxima were observed $\pm 3 \mathrm{~h}$ of sunset, with the peak frequency in rural (urban) cooling occurring $1-2 \mathrm{~h}(2-3 \mathrm{~h})$ after sunset. Moreover, each rural peak consistently led its corresponding urban peak by $1-2 \mathrm{~h}$ (except for summer good dates, when nocturnal UHIs were frequently precluded by early-evening convective precipitation). Such a regular lag (and dissimilar cooling rates) between rural and 
TABLE 4. Annual and seasonal means of the maximum cooling and maximum heating rates at WAD (rural reference) and GAR (urban) for all good and optimal dates. The months defining each season are listed in parentheses. See the text for parameter and time period definitions.

\begin{tabular}{|c|c|c|c|c|c|c|c|c|}
\hline \multirow[b]{3}{*}{ Season } & \multicolumn{4}{|c|}{ Max nocturnal cooling $\left({ }^{\circ} \mathrm{Ch}^{-1}\right)$} & \multicolumn{4}{|c|}{ Max daytime heating $\left({ }^{\circ} \mathrm{Ch}^{-1}\right)$} \\
\hline & \multicolumn{2}{|c|}{ Good dates } & \multicolumn{2}{|c|}{ Optimal dates } & \multicolumn{2}{|c|}{ Good dates } & \multicolumn{2}{|c|}{ Optimal dates } \\
\hline & WAD & GAR & WAD & GAR & WAD & GAR & WAD & GAR \\
\hline Annual & -1.6 & -1.2 & -2.3 & -1.5 & 1.9 & 1.4 & 2.8 & 2.1 \\
\hline Winter (DJF) & -1.6 & -1.0 & -2.2 & -1.3 & 2.0 & 1.4 & 3.0 & 2.1 \\
\hline Spring (MAM) & -1.5 & -1.2 & -2.1 & -1.5 & 1.8 & 1.4 & 2.7 & 2.0 \\
\hline Summer (JJA) & -1.5 & -1.2 & -2.1 & -1.5 & 1.6 & 1.3 & 2.3 & 1.7 \\
\hline Autumn (SON) & -1.8 & -1.3 & -2.6 & -1.8 & 2.1 & 1.6 & 3.2 & 2.4 \\
\hline
\end{tabular}

urban sites can be attributed to urban heat storage that maintains a positive sensible heat flux for 3-4h after sunset (Grimmond and Oke 1999). These heat storage contributions are primarily determined by site-dependent SVF and LULC characteristics but tend to be largest in summer because of longer days and greater solar irradiances (Chow et al. 2014). The smaller maximum cooling rates (Table 4) and greater frequency of urban cooling maxima 3-4 h after sunset on optimal summer dates (Fig. 7d) are consistent with appreciable heat storage effects.

\section{c. Daily variability}

Relationships between UHIs and local weather were first document by Sundborg (1950) for Uppsala, Sweden, where the nocturnal UHII was inversely related to CLC and WS. Subsequently, numerous studies have documented various day-to-day relationships between UHII and weather or air-quality parameters. Here, we focus on the nocturnal heat island and explore daily relationships between $\mathrm{UHII}_{\mathrm{GAR}-\mathrm{NOCT}}$ and $\mathrm{WS}_{\mathrm{AVG}} \mathrm{NOCT}_{\text {, }}$ $\mathrm{CLC}_{\text {AVG-NOCT }}, \mathrm{CLB}_{\text {AVG-NOCT }}, \mathrm{WXF}_{\text {AVG-NOCT }}, \mathrm{RH}_{\text {AVG-NOCT }}$, $\mathrm{STB}_{\text {AVG-NOCT, }} \mathrm{SR}_{\text {GAR-DAY }}, \mathrm{NOX}_{\text {GAR-DAY }}$, and $\mathrm{WD}_{\text {GAR-NOCT }}$ on all good dates via box-and-whisker plots of UHII $_{\text {GAR-NOCT }}$ after each parameter has been stratified into bins with sufficient sample size (Figs. 8-10). Similarly binned distributions for optimal dates (not shown, except for the bin means) confirm the good date relationships. Table 5 provides the cross-correlation coefficients among parameters on good dates. Because of multiple confounding relationships, no attempt was made to isolate effects of any individual parameter (e.g., Runnalls and Oke 2000). Our focus will remain on GAR, where the largest UHIIs were observed.

Various inverse relationships between UHII and both CLC and WS have been documented for a spectrum of urban areas, but no consensus has been reached as to which parameter is more impactful (Ackerman 1985; Svensson and Eliasson 2002), which functional form best describes each relationship (Eliasson 1996; Runnalls and Oke 2000; Morris et al. 2001), or the critical wind speed beyond which UHIIs become negligible (Alonso et al. 2003; Camilloni and Barrucand 2012). Figures $8 \mathrm{a}$ and $8 \mathrm{~b}$ also show inverse relationships for the CMR, whereby $\mathrm{UHII}_{\text {GAR-NOCT }}$ often exceeded $2^{\circ} \mathrm{C}$ when either CLC $_{\text {AVG-NOCT }}$ or $\mathrm{WS}_{\mathrm{AVG}-\mathrm{NOCT}}$ were less than 4 oktas or $2 \mathrm{~m} \mathrm{~s}^{-1}$, respectively. The CLC $\mathrm{AVG-NOCT}$ relationship exhibits linear form, while the $\mathrm{WS}_{\mathrm{AVG}-\mathrm{NOCT}}$ relationship exhibits a slight nonlinearity that becomes asymptotic at wind speeds $>5 \mathrm{~m} \mathrm{~s}^{-1}$ and $<0.5 \mathrm{~m} \mathrm{~s}^{-1}$. Various nonlinear functional forms (e.g., power, exponential, and polynomial) were examined, but none provided a significantly

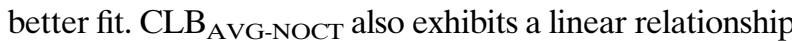
(Fig. 8c), whereby UHII GAR-NOCT $_{\text {often (rarely) exceeded }}$ $2^{\circ} \mathrm{C}$ when low-level cloud layers were absent (present). Collectively, these results reinforce the notion that surface winds and cloud cover/height/type can have a strong influence on nocturnal UHII through turbulent mixing and longwave radiative (greenhouse) effects.

The WXF was proposed as a simple metric to evaluate the combined effects of WS and CLC on UHII. Figure $8 \mathrm{~d}$ shows a strong linear relationship, whereby $\mathrm{UHII}_{\mathrm{GAR}-\mathrm{NOCT}}$ often (rarely) exceeded $2^{\circ} \mathrm{C}$ when $\mathrm{WXF}_{\text {AVG-NOCT }}$ was $>0.8(<0.4)$. Furthermore, consistent with previous studies (Runnalls and Oke 2000; Giovannini et al. 2011), the WXF explained a greater percentage of the total variability in nocturnal UHII than either WS or CLC (see also Table 5). However, considerable day-to-day variability remains, suggesting other factors (meteorological and nonmeteorological) play significant roles in UHII modulation.

For example, it is well known that atmospheric moisture can influence surface air temperatures via radiative effects, and a few studies have documented weak, statistically significant, inverse relationships between UHII and regional RH (Kim and Baik 2002; Hoffmann et al. 2012; Schatz and Kucharik 2014). Figure 9a shows an inverse linear relationship, whereby $\mathrm{UHII}_{\mathrm{GAR}-\mathrm{NOCT}}$ often (rarely) exceeded $2^{\circ} \mathrm{C}$ when $\mathrm{RH}_{\mathrm{AVG}-\mathrm{NOCT}}$ was $<70 \%(>90 \%)$. However, in contrast to the cited studies, RH explained a nearly equivalent percentage of 

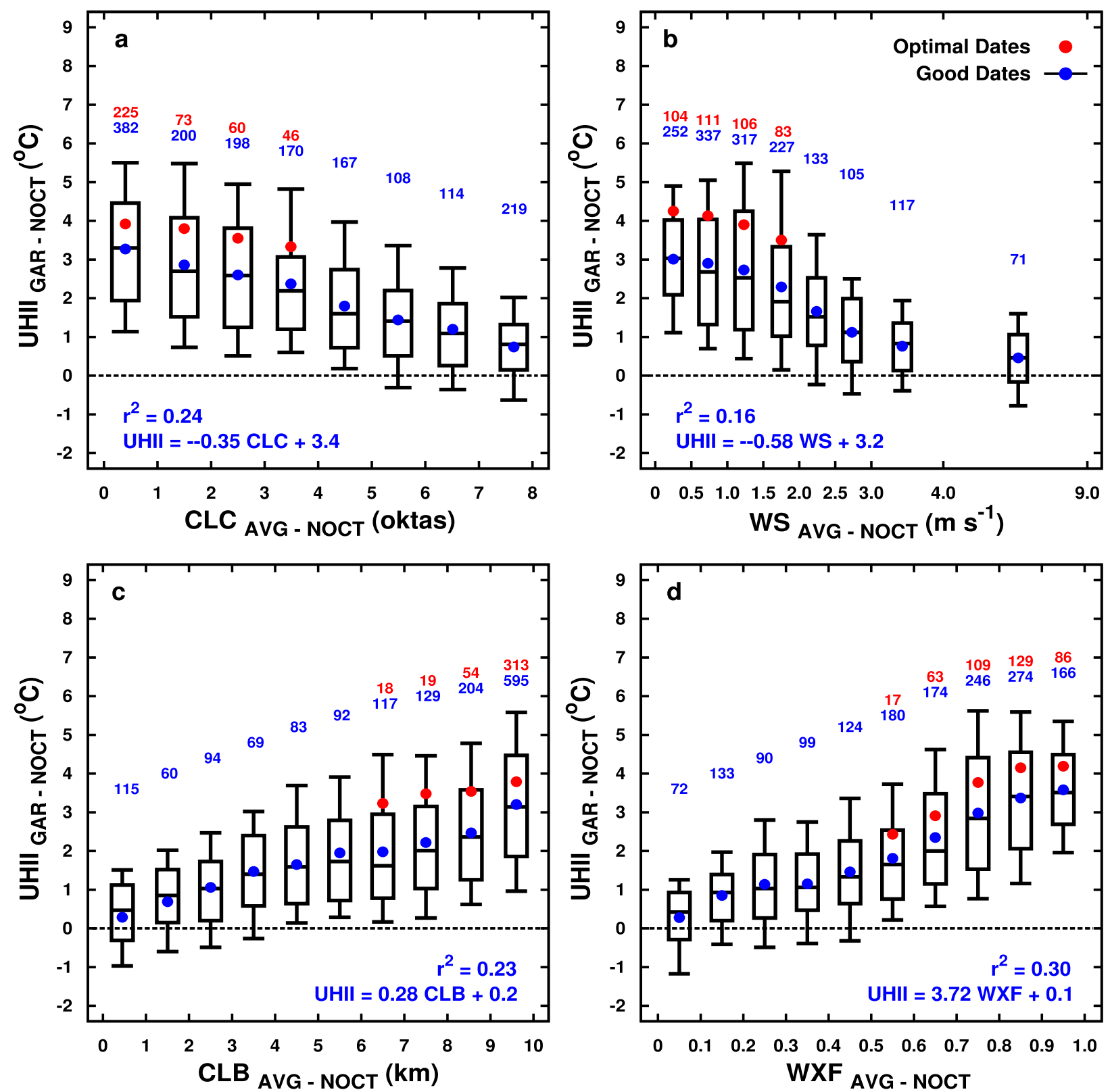

FIG. 8. Box-and-whisker plots of nocturnal mean UHI intensity at GAR as a function of average nocturnal mean (a) cloud cover, (b) wind speed, (c) cloud-base height, and (d) weather factor across the region for all good dates stratified into bins by parameter magnitude. Labels on the horizontal axes define the bin ranges for each parameter. Also shown are the distribution means (circles) and samples sizes (numbers) of each bin for good (blue) and optimal (red) dates, as well as the linear regression statistics for good dates. See the text for parameter and subscript definitions.

the total nocturnal UHII variability (relative to WS or CLC). Such greater relative influence on the CMR heat island is consistent with a strong seasonal relationship often observed between UHII and RH (i.e., wet/dry seasons) in tropical or subtropical cities (Roth 2007).

Intense UHIs are often observed on nights with strong low-level inversions (Gedzelman et al. 2003; Alonso et al. 2003; Holmer et al. 2013; Heisler et al. 2016). Figure $9 \mathrm{~b}$ shows a strong linear relationship between

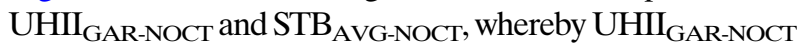
was greater than $2^{\circ} \mathrm{C}$ when STB $_{\text {AVG-NOCT }}$ was stable or extremely stable $(\geq 6)$. In contrast, when $\mathrm{STB}_{\mathrm{AVG}-\mathrm{NOCT}}$ was near neutral $(\leq 5)$, the UHII was often less than $2^{\circ} \mathrm{C}$. Interestingly, note that both STB and WXF exhibit similar 

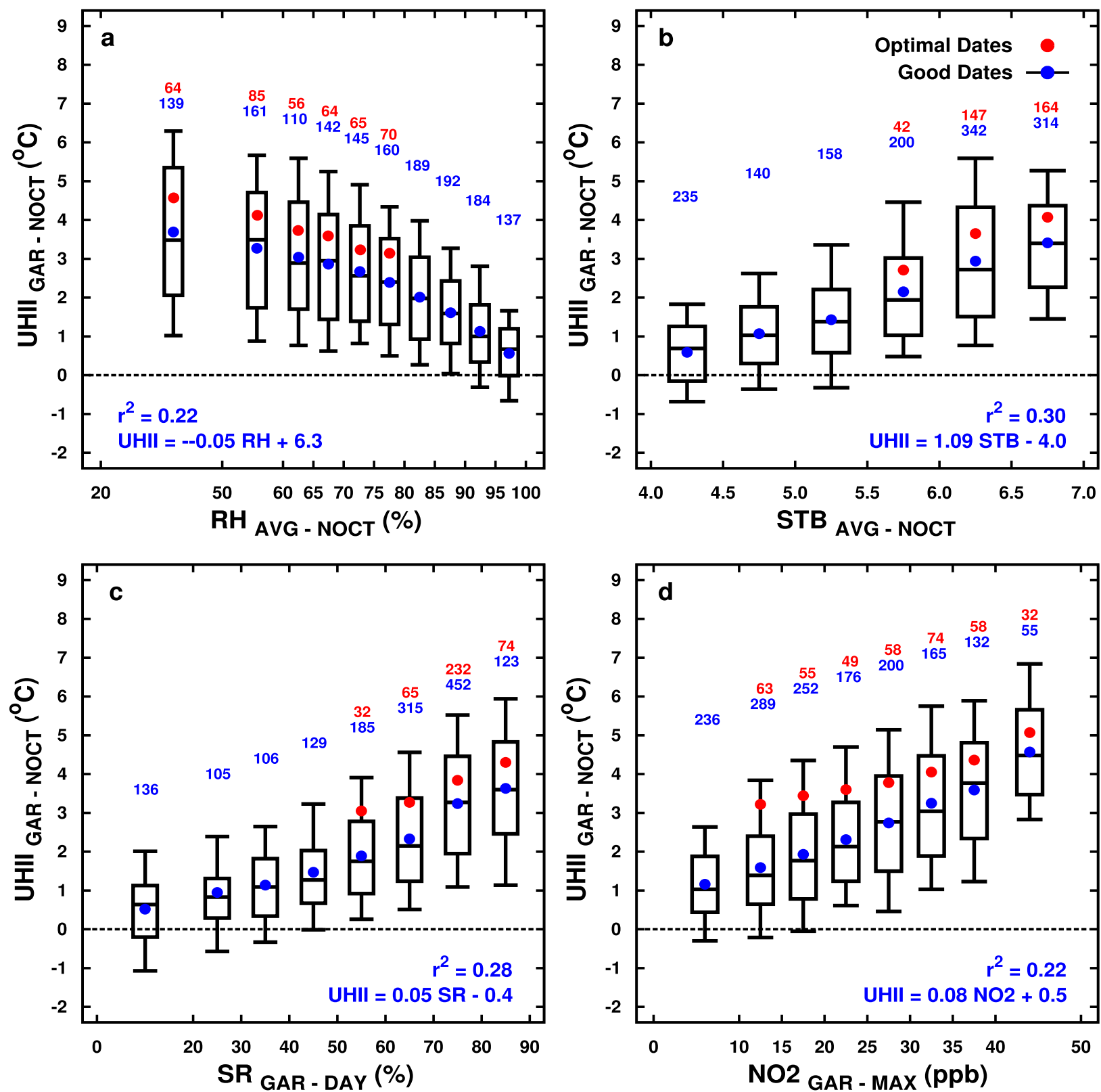

FIG. 9. As in Fig. 8, but as a function of (a) average nocturnal mean stability index, (b) average nocturnal mean relative humidity, (c) observed percentage of the total possible solar radiation on the previous day, and (d) maximum 1-h mean nitrogen dioxide concentration.

relationships with nocturnal UHII (linear; $r^{2}=0.30$ ) and are strongly cross correlated $(r=0.98$; Table 5), but STB can be easily computed from standard WS and CLC observations while WXF requires nonstandard information on cloud type. Thus, STB appears to be an equally effective, but simpler, meteorological metric for UHII analysis.

Steeneveld et al. (2011) and Martin et al. (2015) recently found nocturnal UHII to be well correlated with the integrated global solar radiation received on the previous day. To evaluate whether a similar relationship exists for the CMR, hourly SR observations at GAR where summed between sunrise and sunset on each good date, and then normalized by the cumulative SR incident at the top of the atmosphere on that date. The resulting parameter (denoted as $\mathrm{SR}_{\mathrm{GAR}-\mathrm{DAY}}$ ) provides a rough estimate of the percentage of total possible SR that could be received at the surface on a given date while accounting for seasonal variations but not atmospheric effects. Figure $9 \mathrm{c}$ shows a strong linear relationship between $\mathrm{UHII}_{\mathrm{GAR}-\mathrm{NOCT}}$ 


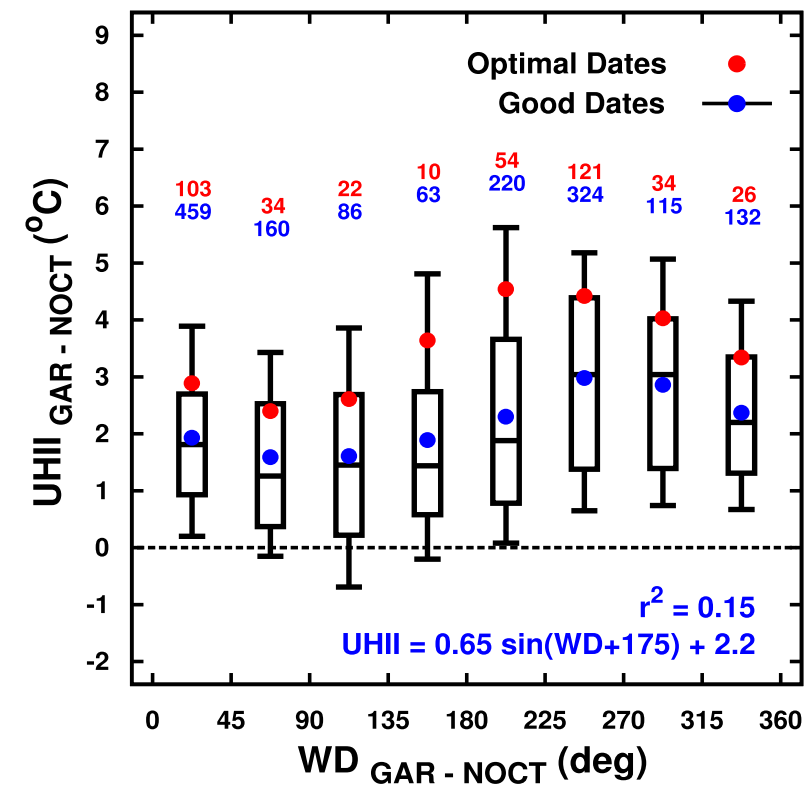

FIG. 10. Similar to Fig. 8, but as a function of the nocturnal mean wind direction and showing the sinusoidal regression statistics for good dates.

and $\mathrm{SR}_{\mathrm{GAR} \text {-DAY }}$, whereby $\mathrm{UHII}_{\mathrm{GAR}-\mathrm{NOCT}}$ often (rarely) exceeded $2{ }^{\circ} \mathrm{C}$ when $\mathrm{SR}_{\mathrm{GAR}-\mathrm{DAY}}$ was $>70 \%(<50 \%)$. Such relationship further supports the notion that greater incoming SR (under dry, clear, and stable conditions; Table 5) leads to greater daytime urban heat storage that subsequently becomes a significant UHI source after sunset (Grimmond and Oke 1999). Our results also suggest $\mathrm{SR}_{\text {GAR-DAY }}$ may serve as an effective short-term predictor for nocturnal UHII.

Air pollution can also influence surface air temperatures via radiative effects. For example, if we focus on the short-term direct radiative effects (those most relevant to daily UHI variability) induced by typical concentrations of the pollutants monitored at GAR, then $\mathrm{NO}_{2}$ has the greatest potential for UHI enhancement ( $\sim 20 \mathrm{ppb}$; equivalent to $\sim 2 \mathrm{~W} \mathrm{~m}^{-2}$ or $\sim 0.2^{\circ} \mathrm{C} \mathrm{day}^{-1}$ of warming in the boundary layer; Vasilkov et al. 2009), while $\mathrm{CO}, \mathrm{O}_{3}, \mathrm{SO}_{2}, \mathrm{PM}_{25}$, and $\mathrm{PM}_{10}$ either would have smaller/negligible warming effects or would weaken UHI via cooling (Mickley et al. 1999; Colls 2002; Heald et al. 2014). Simmonds and Keay (1997) explored daily variations in nocturnal UHII relative to the maximum $\mathrm{NO}_{2}$ concentration observed in Melbourne, Australia, and found a positive correlation during precipitationfree periods when stable anticyclones and light winds prevailed (i.e., optimal dates). For the CMR, Fig. 9d shows a strong linear relationship between $\mathrm{UHII}_{\text {GAR-NOCT }}$ and the maximum 1-h mean $\mathrm{NO}_{2}$ concentration observed at GAR (denoted as $\mathrm{NO} 2_{\text {GAR-MAX}}$ ) on good dates,

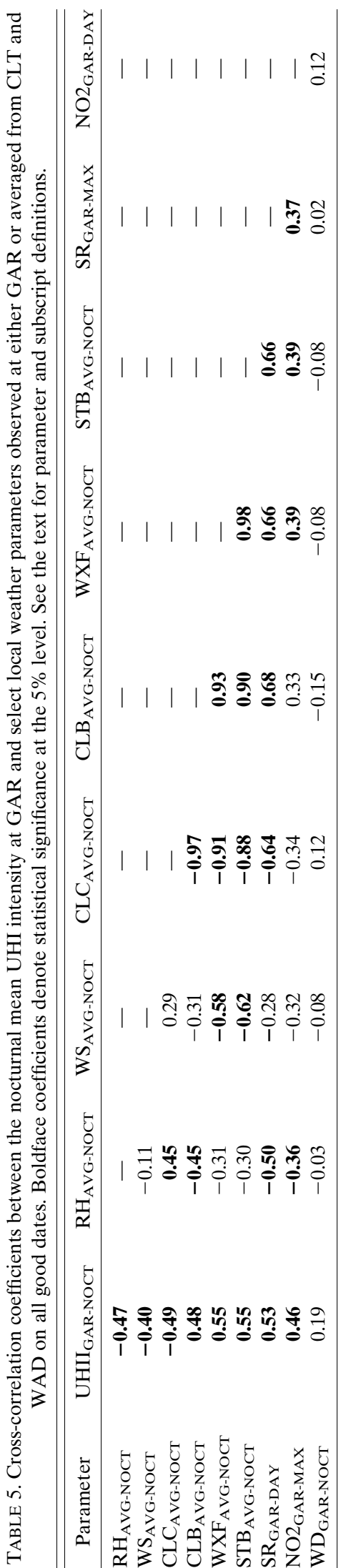


TABLE 6. Average nocturnal mean UHI intensity at GAR and select weather parameters for weekdays and weekends among good and optimal dates. Also included are the number $(N)$ of dates within each subset. Boldface values denote means that are significantly different from their weekly counterpart at the $95 \%$ level. See the text for parameter and subscript definitions.

\begin{tabular}{|c|c|c|c|c|c|}
\hline \multirow[b]{2}{*}{ Parameter } & \multirow[b]{2}{*}{ Units } & \multicolumn{2}{|c|}{ Good dates } & \multicolumn{2}{|c|}{ Optimal dates } \\
\hline & & Weekdays & Weekends & Weekdays & Weekends \\
\hline$N$ & - & 1113 & 445 & 308 & 96 \\
\hline UHII $_{\text {GAR-NOCT }}$ & ${ }^{\circ} \mathrm{C}$ & 2.39 & 2.19 & 3.97 & 3.01 \\
\hline $\mathrm{RH}_{\text {AVG-NOCT }}$ & $\%$ & 75.1 & 74.7 & 62.3 & 63.1 \\
\hline $\mathrm{WS}_{\mathrm{AVG}-\mathrm{NOCT}}$ & $\mathrm{m} \mathrm{s}^{-1}$ & 1.6 & 1.5 & 1.1 & 1.2 \\
\hline CLC $_{\text {AVG-NOCT }}$ & oktas & 3.5 & 3.3 & 1.2 & 1.5 \\
\hline $\mathrm{CLB}_{\text {AVG-NOCT }}$ & $\mathrm{m}$ & 6780 & 6960 & 9470 & 9210 \\
\hline $\mathrm{WXF}_{\text {AVG-NOCT }}$ & - & 0.6 & 0.6 & 0.8 & 0.8 \\
\hline STB $_{\text {AVG-NOCT }}$ & - & 5.7 & 5.7 & 6.5 & 6.4 \\
\hline $\mathrm{SR}_{\mathrm{GAR}-\mathrm{DAY}}$ & $\%$ & 56.6 & 58.1 & 74.9 & 72.3 \\
\hline $\mathrm{NO} 2_{\text {GAR-MAX }}$ & $\mathrm{ppb}$ & 21.4 & 19.2 & 27.2 & 22.8 \\
\hline $\mathrm{PR}_{\mathrm{AVG}-\mathrm{NOCT}}$ & $\mathrm{mm}$ & 1.3 & 1.2 & 0.0 & 0.0 \\
\hline
\end{tabular}

whereby UHII $\mathrm{GAR}_{\mathrm{NOCT}}$ often (rarely) exceeded $2^{\circ} \mathrm{C}$ when NO2 Gar-max was $>30 \mathrm{ppb}(<10 \mathrm{ppb})$, and greater $\mathrm{NO} 2_{\mathrm{GAR}-\mathrm{MAx}}$ occur under dry, calm, clear, and stable conditions (Table 5). Thus, our results extend those of Simmonds and Keay (1997), while further suggesting $\mathrm{NO} 2_{\mathrm{GAR}-\mathrm{MAX}}$ may serve as another effective predictor of nocturnal UHII (since maximum $\mathrm{NO}_{2}$ concentrations often occur midmorning).

Finally, the prevailing wind direction can influence nocturnal UHII if the urban core (or observation site) is located downstream of a nearby coastline (Murphy et al. 2011), mountain range (Comrie 2000), prominent valley (Acero et al. 2013), or another urban area (Zhang et al. 2011). Figure 10 shows a modest sinusoidal relationship between UHII $_{\text {GAR-NOCT }}$ and $\mathrm{WD}_{\text {GAR-NOCT }}$ on good dates, whereby UHII $_{\text {GAR-NOCT }}$ often (rarely) exceeded $2^{\circ} \mathrm{C}$ with westerly (easterly) surface winds. The most intense UHIs occurred with west-southwesterly flow $\left(225^{\circ}-270^{\circ}\right)$. Since the CMR is relatively flat and GAR is located more than $100 \mathrm{~km}$ from any prominent coasts, mountains, valleys, or urban areas, such modest relationship likely reflects the advection of a UHI maximum from the CMR urban core toward the GAR site (distance $=5.4 \mathrm{~km}$; Fig. 1 ).

\section{d. Intra-weekly variability}

Human activity is organized on a weekly cycle. Here, we examine whether the CMR heat island exhibits a significant intensity difference between traditional workdays (or weekdays) and traditional rest days (or weekends). All good and optimal dates were partitioned into weekday and weekend groups. National holidays were included in the weekend group. Table 6 shows the mean $\mathrm{UHII}_{\mathrm{GAR} \text {-NOCT }}$ on weekdays and weekends for good and optimal dates, as well as the corresponding mean values for select weather and air-quality parameters.
On good dates, all weekday-weekend differences were small and statistically insignificant. In contrast, on optimal dates, the differences between weekday $\mathrm{UHII}_{\mathrm{GAR}-\mathrm{NOCT}}$ and $\mathrm{NO} 2_{\mathrm{GAR}-\mathrm{MAX}}$ were significantly larger than their weekend counterparts (while the other weather parameters continued to show insignificant differences). Such results confirm that UHII and $\mathrm{NO}_{2}$ are linked (at times) to the weekly cycle of human activity, whereas weather remains linked more to natural variability.

Variations in weekly human activity are most directly linked to the transportation and energy sectors, including their emissions. The primary urban sources for $\mathrm{NO}_{2}$ are fossil fuel combustion by motor vehicles and second-order photochemical reactions, while urban sinks include advection, convection, oxidation, wet deposition, and photochemical reactions involving ozone (Colls 2002). Moreover, $\mathrm{NO}_{2}$ has a typical lifetime of $\sim 1$ day but lifetimes are longer (i.e., concentrations are greater) in winter because of a smaller photochemical sink (shorter days and less incoming radiation; Ordóñez et al. 2006). Thus, on weekdays with optimal weather conditions, $\mathrm{NO}_{2}$ sources in the urban boundary layer should exceed sinks, allowing greater concentrations to make appreciable UHII enhancements. When optimal dates were further partitioned into specific days (Fig. 11), the NO2 $2_{\text {GAR-MAX }}$ distributions exhibited a small increase (or $\mathrm{NO}_{2}$ accumulation) during the work week (e.g., means increased from $\sim 20 \mathrm{ppb}$ on Mondays to $\sim 25 \mathrm{ppb}$ on Fridays) before dropping to a weekend minimum $(\sim 16 \mathrm{ppb})$ on Sundays. Workday differences in $\mathrm{UHII}_{\mathrm{GAR} \text {-NOCT }}$ were less pronounced, but the weekly maximum mean $\left(4.2^{\circ} \mathrm{C}\right)$ was observed on Friday, followed by a Sunday minimum $\left(2.8^{\circ} \mathrm{C}\right)$. These results are broadly consistent with the intra-weekly UHI analyses of Simmonds and Keay (1997) and Kim and Baik (2005). 


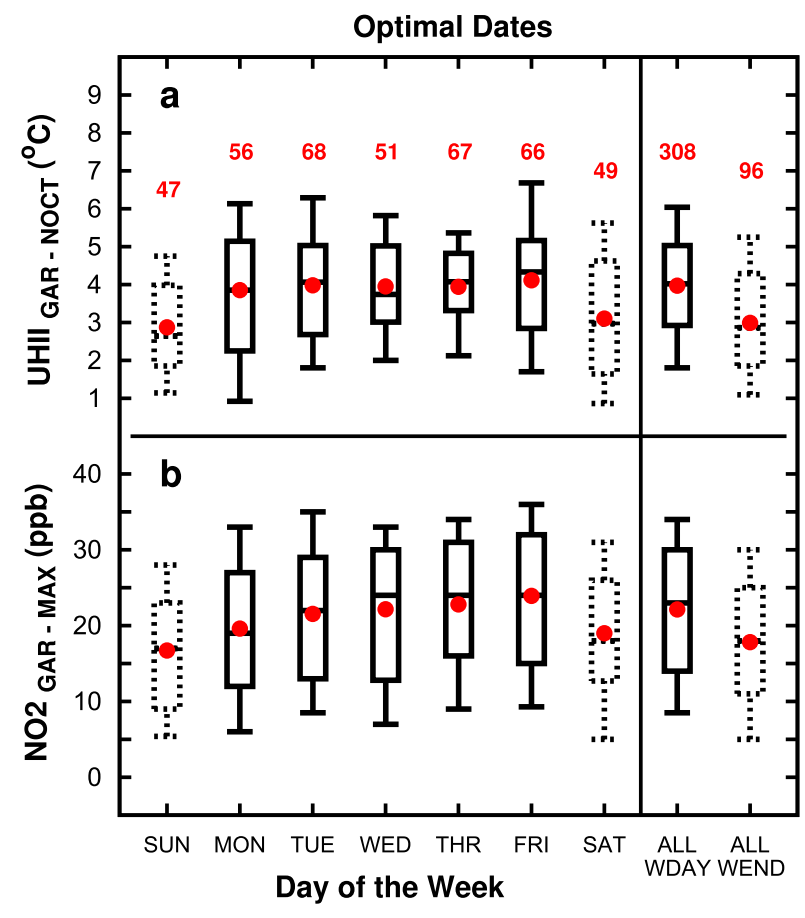

FIG. 11. Box-and-whisker plots of the (a) nocturnal mean UHI intensity at GAR and (b) maximum 1-h mean nitrogen dioxide concentration at GAR for all optimal dates as a function of the day of the week. Combined distributions for all weekly workdays (WDAY; solid) and weekend days (WEND; dashed) are also shown, as are the distribution means (red circles) and sample sizes (numbers) for each day of the week. See the text for parameter and subscript definitions.

\section{e. Monthly-seasonal variability}

One of the most documented characteristics of nocturnal UHIs has been their monthly or seasonal variability. In temperate climates, intense UHIs often occur in the warm season when optimal weather conditions are common, and solar radiation, nocturnal heat fluxes from daytime storage, and urban-rural vegetation contrasts are greatest (Arnfield 2003; Imhoff et al. 2010). In tropical climates, intense UHIs most often occur during the dry season when optimal weather conditions are common and rural thermal admittances are reduced (Roth 2007). Figure 12 shows the monthly variability of UHII GAR-NOCT $_{\text {for all good and optimal dates across }}$ the CMR, that is, in a humid-subtropical climate. Overall, monthly mean UHII $_{\text {GAR-NOCT }}$ were largest in the cold-dry season (October-March; Figs. 2 and 4), reaching a maximum $\left(2.6^{\circ} \mathrm{C}\right.$ for good dates; $4.2^{\circ} \mathrm{C}$ for optimal dates) in November, because of $\sim 25 \%$ of good dates (and $\sim 50 \%$ of optimal dates) exhibiting $\mathrm{UHII}_{\mathrm{GAR} \text {-NOCT }}$ greater than $4.0^{\circ} \mathrm{C}$. In contrast, during the warm-moist season (April-September), less than $10 \%$ of good dates (and only $32 \%$ of optimal dates)

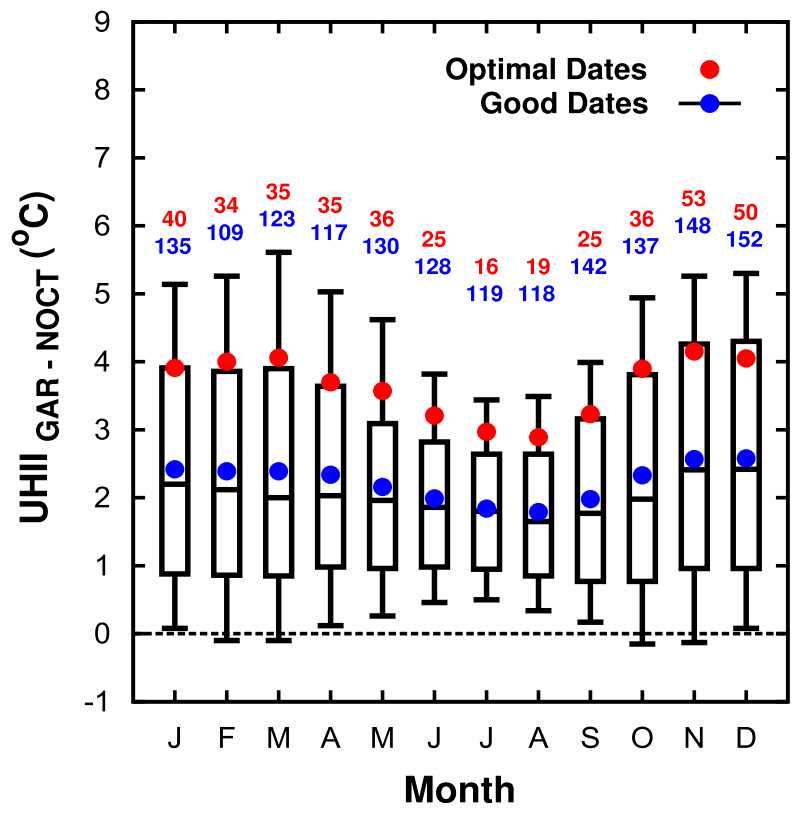

FIG. 12. Box-and-whisker plots of nocturnal mean UHI intensity at GAR for all good dates as a function of month. Also shown are the monthly means (circles) and sample sizes (numbers) for good (blue) and optimal (red) dates. See the text for parameter and subscript definitions.

exhibited UHII $\mathrm{GAR}_{\text {-NOCT }}$ greater than $4.0^{\circ} \mathrm{C}$, despite lighter winds (see Fig. 2). Such seasonality is consistent with UHI observations for other humid-subtropical (Cfa) cities without topographic modulation (Figuerola and Mazzeo 1998; Sakakibara and Owa 2005), and further supports the notion that atmospheric moisture plays a significant role in UHII modulation.

\section{f. Interannual variability}

Efforts to detect and remove urban signatures from longterm temperature records used in the assessment of naturalanthropogenic climate change (Karl et al. 1988; Peterson 2003) have motivated several analyses of UHII trends and interannual variability. Over the last 30-80 yr of the twentieth century, most cities exhibited a statistically significant positive trend in annual mean UHII ranging from $0.05^{\circ}$ to $0.60^{\circ} \mathrm{Cdecade}^{-1}$ (Kukla et al. 1986; Chen et al. 2003; Wilby 2003; Velazquez-Lozada et al. 2006; Stone 2007), while others exhibited no trend (Böhm 1998) or a negative trend (Camilloni and Barrucand 2012). The positive trends were often attributed to rapid growth, increases in air pollution and/or anthropogenic heat release, and decreases in urban vegetation, whereas negative trends were attributed to a decrease in the frequency of optimal weather conditions for UHI development. Here, we examine whether the rapidly growing CMR exhibited a significant

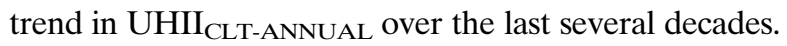




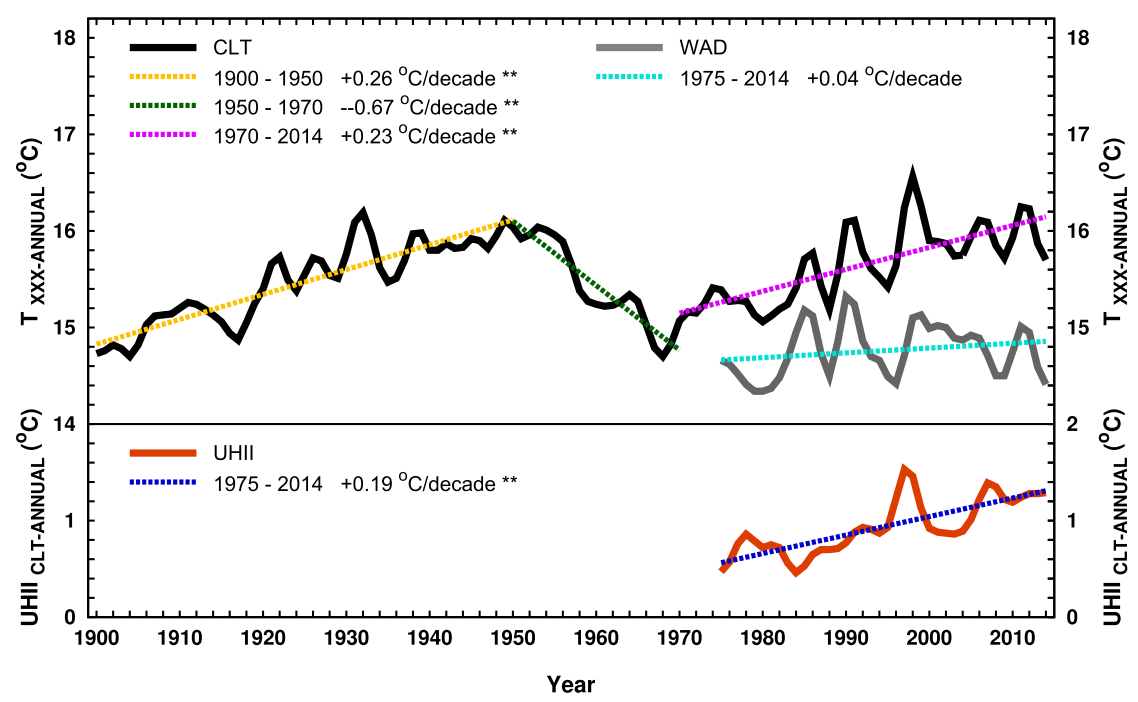

FIG. 13. Time series of annual mean temperature at CLT (black) and WAD (gray) as well as the annual mean UHI intensity at CLT (red). Trend lines (dashed) are shown for periods with consistent regional land-use practices (see text) while asterisks denote trends significant at the $95 \%$ level. See the text for parameter and subscript definitions.

Figure 13 shows the time series of available $T_{\text {CLT-ANNUAL }}$ and $T_{\text {WAD-ANNUAL }}$ for the $1900-2014$ period. The $T_{\text {CLT-AnNual }}$ exhibits the distinct multidecadal pattern-early-century warming (1900-50) followed by midcentury cooling (1950-70) and contemporary warming (1970-2014) —often observed in regional and global temperatures (Jones et al. 1999). During the recent warming, $T_{\text {CLT-ANNUAL }}$ exhibited a statistically significant positive trend $\left(0.23^{\circ} \mathrm{Cdecade}^{-1}\right)$, while the available. $T_{\text {WAD-ANNUAL }}(1975-2014)$ showed an insignificant positive trend $\left(0.04^{\circ} \mathrm{C}\right.$ decade $\left.^{-1}\right)$, despite a strong correlation with $T_{\text {CLT-ANNUAL }}(r=0.86)$. As a result, UHII $_{\text {CLT-ANNUAL }}$ exhibited a statistically significant positive trend $\left(0.19^{\circ} \mathrm{Cdecade}^{-1}\right)$ over the 1975 2014 period, consistent with other analyses (e.g., Stone 2007). Moreover, the increasing UHII coincided with rapid population growth and urbanization (Meentemeyer et al. 2013; Singh et al. 2012), suggesting that increased anthropogenic heating and reduced urban vegetation contributed. Whether an increase in the frequency of optimal weather across the region further contributed (László et al. 2016) cannot be determined because of insufficient climatological RH, WS, CLC, and PR observations.

\section{Summary and concluding remarks}

Observations from surface weather and air-quality stations were used to analyze the multiscale temporal variability of the Charlotte urban heat island. Located on level rolling terrain in a humid-subtropical climate,
Charlotte has experienced rapid population growth and considerable urbanization over the past three decades. Our specific findings include the following:

1) Prominent nocturnal UHIs were common. Over $70 \%$ of all dates during the 5-yr study period exhibited nocturnal mean UHII $>1{ }^{\circ} \mathrm{C}$. The most intense UHIs $\left(>4^{\circ} \mathrm{C}\right)$ often occurred on nights with light winds $\left(<2.0 \mathrm{~m} \mathrm{~s}^{-1}\right)$, clear-scattered cloud cover $(<4$ oktas), low humidity $(<80 \%)$, and no precipitation or frontal passages-conditions optimal for UHI development.

2) Diurnal UHII maxima often occurred $\pm 2 \mathrm{~h}$ of sunrise. Prominent secondary maxima observed $\pm 4 \mathrm{~h}$ of sunset in the warm (cold) season were attributed to early-evening precipitation (early-evening anthropogenic heating and rural dewfall).

3) Mean rural cooling reached a maximum $1-2 \mathrm{~h}$ after sunset while urban cooling was less intense and lagged by $1-2 \mathrm{~h}$. Maximum seasonal differences in rural-urban cooling occurred in winter and were attributed to a positive sensible heat flux maintained for 3-4 $\mathrm{h}$ after sunset by the release of heat stored in built urban surfaces during the daytime.

4) Daily variations in nocturnal mean UHII exhibited statistically significant positive (negative) correlations with cloud-base height, weather factor, atmospheric stability, $\mathrm{NO}_{2}$ concentration, and total solar radiation (relative humidity, wind speed, and cloud cover), suggesting that local weather and air quality have a strong influence on nocturnal UHII variability. 
5) When optimal weather conditions for UHI development were present, UHIIs were more intense on weekdays than on weekends. A strong positive correlation with urban boundary layer $\mathrm{NO}_{2}$ concentrations suggests that appreciable short-term UHII enhancements can result from the pollution emitted by motor vehicles and other fossil fuel combustion processes.

6) On monthly-seasonal scales, the most intense UHIs often occurred during the winter dry season (October-March), further supporting the notion that atmospheric moisture plays a significant role in UHII modulation for humid climates.

7) On interannual scales, the UHII exhibited a statistically significant positive trend $\left(0.19^{\circ} \mathrm{C}\right.$ decade $\left.^{-1}\right)$ during 1975-2014, suggesting increased anthropogenic heating and reduced urban vegetation (from population growth and urbanization) contributed to the UHII increase.

8) These results build upon the growing body of evidence that weather, air pollution, and changes in urban form can modulate UHI intensities over various time scales.

The current analysis, a first step for the CMR, focused on linear relationships between individual parameters and UHII, but complex multiparameter interactions can produce nonlinear feedbacks. For example, on optimal dates, strong low-level stability restricts vertical mixing in above the boundary layer, which limits cloud formation, air pollution sinks, and the downward transport of stronger winds, while increasing the cumulative incident solar radiation and surface heat storage. Moreover, UHIs often induce a modest urban-breeze circulation (e.g., Hidalgo et al. 2010), whereby low-level convergence toward the urban core can further concentrate pollutants, humidity, and warm air. Since this shallow circulation is a hydrostatic response to the integrated UHII, such collective processes embody a nonlinear feedback scenario that simultaneously enhances multiple factors conducive to intense UHI development. The common observance of intense UHIs on cloud-free dates with stable anticyclones, calm winds, and increased air pollution (Arnfield 2003; Roth 2007) supports this scenario. Furthermore, numerical simulations suggest additional urbanization could accelerate the feedback loop (via increased heat storage, a more intense UHI, and a stronger circulation) and either enhance UHII ( $\mathrm{Li}$ et al. 2015) or induce deep convection that moderates UHII via cold downdrafts (Ryu et al. 2013). Additional analyses are needed to clarify critical processes during such nonlinear feedback scenarios.

Finally, while the UHI variability reported herein exhibits many commonalities with other cities, our results also support the notion that each city has unique UHI characteristics linked to complex local interactions among climatic and meteorological conditions, human activity, and urban form (Grimmond 2007). Better understanding of such uniqueness will benefit local urban planning and climate change mitigation efforts. Ongoing work for the CMR involves analysis of the UHI spatial structure, synoptic climatology, and impacts on precipitation, energy use, and ecology, as well as urban cool-island and moisture-excess events.

Acknowledgments. This study grew out of a graduatelevel urban meteorology course taught by the lead author at UNC Charlotte in 2014. We are grateful to Gang Chen for computing the sky-view factors and to Brian Magi for discussions on air pollution. Comments from three anonymous reviewers were helpful. This work was supported through grants from the University of North Carolina at Charlotte Faculty Research Program and the JMW Foundation.

\section{REFERENCES}

Acero, J. A., J. Arrizabalaga, S. Kupski, and L. Katzschner, 2013: Urban heat island in a coastal urban area in northern Spain. Theor. Appl. Climatol., 113, 137-154, https://doi.org/10.1007/ s00704-012-0774-z.

Ackerman, B., 1985: Temporal march of the Chicago heat island. J. Climate Appl. Meteor., 24, 547-554, https://doi.org/10.1175/ 1520-0450(1985)024<0547:TMOTCH >2.0.CO;2.

Alonso, M. S., J. L. Labajo, and M. R. Fidalgo, 2003: Characteristics of the urban heat island in the city of Salamanca, Spain. Atmósfera, 16, 137-148.

Arnfield, A. J., 2003: Two decades of urban climate research: A review of turbulence, exchanges of energy and water, and the urban heat island. Int. J. Climatol., 23, 1-26, https://doi.org/ 10.1002/joc.859.

Ashley, W. S., M. L. Bentley, and J. A. Stallins, 2012: Urban-induced thunderstorm modification in the southeast United States. Climatic Change, 113, 481-498, https://doi.org/10.1007/ s10584-011-0324-1.

Basara, J. B., P. K. Hall Jr., A. J. Schroeder, B. G. Illston, and K. L. Nemunaitis, 2008: Diurnal cycle of the Oklahoma City urban heat island. J. Geophys. Res., 113, D20109, https://doi.org/ 10.1029/2008JD010311.

Böhm, R., 1998: Urban bias in temperature time series-A case study for the city of Vienna, Austria. Climatic Change, 38, 113-128, https://doi.org/10.1023/A:1005338514333.

Brandsma, T., and D. Wolters, 2012: Measurement and statistical modeling of the urban heat island of the city of Utrecht (the Netherlands). J. Appl. Meteor. Climatol., 51, 1046-1060, https://doi.org/10.1175/JAMC-D-11-0206.1.

Brown, P. J., and A. T. DeGaetano, 2010: Using discriminant analysis to classify urban and rural climate stations based on diurnal range of temperature and dewpoint depression. J. Appl. Meteor. Climatol., 49, 2366-2379, https://doi.org/ 10.1175/2010JAMC2458.1.

Camilloni, I., and M. Barrucand, 2012: Temporal variability of the Buenos Aires, Argentina, urban heat island. Theor. Appl. Climatol., 107, 47-58, https://doi.org/10.1007/s00704-011-0459-z. 
Chen, F., and Coauthors, 2012: Research priorities in observing and modeling urban weather and climate. Bull. Amer. Meteor. Soc., 93, 1725-1728, https://doi.org/10.1175/BAMS-D-11-00217.1.

Chen, L., W. Zhu, X. Zhou, and Z. Zhou, 2003: Characteristics of the heat island effect in Shanghai and its possible mechanism. $A d v$. Atmos. Sci., 20, 991-1001, https://doi.org/10.1007/BF02915522.

—, E. Ng, X. An, C. Ren, M. Lee, U. Wang, and Z. He, 2012: Sky view factor analysis of street canyons and its implications for daytime intra-urban air temperature differentials in high-rise, high-density urban areas of Hong Kong: A GIS-based simulation approach. Int. J. Climatol., 32, 121-136, https://doi.org/ 10.1002/joc.2243.

Chow, W. T. L., and M. Roth, 2006: Temporal dynamics of the urban heat island of Singapore. Int. J. Climatol., 26, 2243-2260, https://doi.org/10.1002/joc.1364.

—_, and B. M. Svoma, 2011: Analyses of nocturnal temperature cooling-rate response to historical local-scale urban land-use/ land cover change. J. Appl. Meteor. Climatol., 50, 1872-1883, https://doi.org/10.1175/JAMC-D-10-05014.1.

, T. J. Volo, E. R. Vivoni, G. D. Jenerette, and B. L. Ruddell, 2014: Seasonal dynamics of a suburban energy balance in Phoenix, Arizona. Int. J. Climatol., 34, 3863-3880, https:// doi.org/10.1002/joc.3947.

Collier, C. G., 2006: The impact of urban areas on weather. Quart. J. Roy. Meteor. Soc., 132, 1-25, https://doi.org/10.1256/qj.05.199.

Colls, J., 2002: Air Pollution. Spon Press, 560 pp.

Comrie, A. C., 2000: Mapping a wind-modified urban heat island in Tucson, Arizona (with comments on integrating research and undergraduate learning). Bull. Amer. Meteor. Soc., 81, 2417-2431, https://doi.org/10.1175/1520-0477(2000)081<2417: MAWMUH $>2.3 . \mathrm{CO} ; 2$.

Dixon, P. G., and T. L. Mote, 2003: Patterns of Atlanta's urban heat island-initiated precipitation. J. Appl. Meteor., 42, 1273-1284, https:// doi.org/10.1175/1520-0450(2003)042<1273:PACOAU>2.0.CO;2.

Eliasson, I., 1996: Intra-urban nocturnal temperature differences: A multivariate approach. Climate Res., 7, 21-30, https:// doi.org/10.3354/cr007021.

Figuerola, P. I., and N. A. Mazzeo, 1998: Urban-rural temperature differences in Buenos Aires. Int. J. Climatol., 18, 1709-1723, https://doi.org/10.1002/(SICI)1097-0088(199812)18:15<1709:: AID-JOC338>3.0.CO;2-I.

Fortuniak, K., K. Klysik, and J. Wibig, 2006: Urban-rural contrasts of meteorological parameters in Łódź. Theor. Appl. Climatol., 84, 91-101, https://doi.org/10.1007/s00704-005-0147-y.

Gallo, K. P., and T. W. Owen, 1999: Satellite-based adjustments for the urban heat island temperature bias. J. Appl. Meteor., 38, 806-813, https://doi.org/10.1175/1520-0450(1999)038<0806: SBAFTU $>2.0 . \mathrm{CO} ; 2$.

Gedzelman, S. D., S. Austin, R. Cermak, N. Stefano, S. Partridge, S. Quesenberry, and D. A. Robinson, 2003: Mesoscale aspects of the urban heat island around New York City. Theor. Appl. Climatol., 75, 29-42, https://doi.org/10.1007/s00704-002-0724-2.

Georgescu, M., 2015: Challenges associated with adaptation to future urban expansion. J. Climate, 28, 2544-2563, https:// doi.org/10.1175/JCLI-D-14-00290.1.

Giovannini, L., D. Zardi, and M. de Franceschi, 2011: Analysis of the urban thermal fingerprint of the city of Trento in the Alps. J. Appl. Meteor. Climatol., 50, 1145-1162, https://doi.org/ 10.1175/2010JAMC2613.1.

Godowitch, J. M., J. K. S. Ching, and J. F. Clarke, 1985: Evolution of the nocturnal inversion layer at an urban and nonurban location. J. Climate Appl. Meteor., 24, 791-804, https://doi.org/ 10.1175/1520-0450(1985)024<0791:EOTNIL>2.0.CO;2.
Grimm, N. B., S. H. Faeth, N. E. Golubiewski, C. L. Redman, J. Wu, X. Bai, and J. M. Briggs, 2008: Global change and the ecology of cities. Science, 319, 756-760, https://doi.org/10.1126/ science.1150195.

Grimmond, C. S. B., 2006: Progress in measuring and observing the urban atmosphere. Theor. Appl. Climatol., 84, 3-22, https:// doi.org/10.1007/s00704-005-0140-5.

_ , and T. R. Oke, 1995: Comparison of heat fluxes from summertime observations in the suburbs of four North American cities. J. Appl. Meteor., 34, 873-889, https://doi.org/10.1175/ 1520-0450(1995)034<0873:COHFFS > 2.0.CO;2.

— servations and evaluation of a simple model. J. Appl. Meteor., 38, 922-940, https://doi.org/10.1175/1520-0450(1999)038<0922: HSIUAL $>2.0 . \mathrm{CO} ; 2$.

Grimmond, S., 2007: Urbanization and global environmental change: Local effects of urban warming. Geogr. J., 173, 83-88, https://doi.org/10.1111/j.1475-4959.2007.232_3.x.

Hansen, J., R. Ruedy, M. Sato, M. Imhoff, W. Lawrence, D. Easterling, T. Peterson, and T. Karl, 2001: A closer look at United States and global surface temperature change. J. Geophys. Res., 106, 23 947-23 963, https://doi.org/10.1029/ 2001JD000354.

Hart, M. A., and D. J. Sailor, 2009: Quantifying the influence of land-use and surface characteristics on spatial variability in the urban heat island. Theor. Appl. Climatol., 95, 397-406, https:// doi.org/10.1007/s00704-008-0017-5.

Hawkins, T. W., A. J. Brazel, W. L. Stefanov, W. Bigler, and E. M. Saffell, 2004: The role of rural variability in urban heat island determination for Phoenix, Arizona. J. Appl. Meteor., 43, 476-486, https://doi.org/10.1175/1520-0450(2004)043<0476: TRORVI $>2.0 . \mathrm{CO} ; 2$.

Heald, C. L., D. A. Ridley, J. H. Kroll, S. R. H. Barrett, K. E. CadyPereira, M. J. Alvarado, and C. D. Holmes, 2014: Contrasting the direct radiative effect and direct radiative forcing of aerosols. Atmos. Chem. Phys., 14, 5513-5527, https://doi.org/ 10.5194/acp-14-5513-2014.

Heisler, G. M., A. Ellis, D. J. Nowak, and I. Yesilonis, 2016: Modeling and imaging land-cover influences on air temperature in and near Baltimore, MD. Theor. Appl. Climatol., 124, 497-515, https://doi.org/10.1007/s00704-015-1416-z.

Hidalgo, J., V. Masson, and L. Gimeno, 2010: Scaling the daytime urban heat island and urban-breeze circulation. J. Appl. Meteor. Climatol., 49, 889-901, https://doi.org/10.1175/2009JAMC2195.1.

Hoffmann, P., and K. H. Schlünzen, 2013: Weather pattern classification to represent the urban heat island in the present and future climate. J. Appl. Meteor. Climatol., 52, 2699-2714, https://doi.org/10.1175/JAMC-D-12-065.1.

_ , O. Krueger, and K. H. Schlünzen, 2012: A statistical model for the urban heat island and its application to a climate change scenario. Int. J. Climatol., 32, 1238-1248, https://doi.org/ $10.1002 /$ joc. 2348 .

Holmer, B., and I. Eliasson, 1999: Urban-rural vapor pressure differences and their role in the development of urban heat islands. Int. J. Climatol., 19, 989-1009, https://doi.org/ 10.1002/(SICI)1097-0088(199907)19:9<989::AIDJOC410>3.0.CO;2-1.

- S. Thorsson, and J. Lindén, 2013: Evening evapotranspirative cooling in relation to vegetation and urban geometry in the city of Ouagadougou, Burkina Faso. Int. J. Climatol., 33, 3089-3105, https://doi.org/10.1002/joc.3561.

Hu, X.-M., P. M. Klein, M. Xue, J. K. Lundquist, F. Zhang, and Y. Qi, 2013: Impact of low-level jets on the nocturnal urban 
heat island intensity in Oklahoma City. J. Appl. Meteor. Climatol., 52, 1779-1802, https://doi.org/10.1175/JAMC-D12-0256.1.

Huff, F. A., and S. A. Changnon, 1973: Precipitation modification by major urban areas. Bull. Amer. Meteor. Soc., 54, 1220-1232, https://doi.org/10.1175/1520-0477(1973)054<1220: PMBMUA $>2.0$.CO;2.

Imhoff, M. L., P. Zhang, R. E. Wolfe, and L. Bounoua, 2010: Remote sensing of the urban heat island effect across biomes in the continental USA. Remote Sens. Environ., 114, 504-513, https://doi.org/10.1016/j.rse.2009.10.008.

Jauregui, E., 1997: Heat island development in Mexico City. Atmos. Environ., 31, 3821-3831, https://doi.org/10.1016/ S1352-2310(97)00136-2.

Jin, S., L. Yang, P. Danielson, C. Homer, J. Fry, and G. Xian, 2013: A comprehensive change detection method for updating the National Land Cover Database to circa 2011. Remote Sens. Environ., 132, 159-175, https://doi.org/10.1016/ j.rse.2013.01.012.

Jones, P. D., M. New, D. E. Parker, S. Martin, and I. G. Rigor, 1999: Surface air temperature and its changes over the past 150 years. Rev. Geophys., 37, 173-199, https://doi.org/10.1029/ 1999RG900002.

Karl, T. R., H. F. Diaz, and G. Kukla, 1988: Urbanization: Its detection and effect in the United States climate record. J. Climate 1, 1099-1123, https://doi.org/10.1175/1520-0442(1988)001<1099: UIDAEI $>2.0 . \mathrm{CO} ; 2$

Kim, Y.-H., and J.-J. Baik, 2002: Maximum urban heat island in Seoul. J. Appl. Meteor., 41, 651-659, https://doi.org/10.1175/ 1520-0450(2002)041<0651:MUHIII>2.0.CO;2.

- and - 2005: Spatial and temporal structure of the urban heat island in Seoul. J. Appl. Meteor., 44, 591-605, https:// doi.org/10.1175/JAM2226.1.

Kukla, G., J. Gavin, and T. R. Karl, 1986: Urban warming. J. Climate Appl. Meteor., 25, 1265-1270, https://doi.org/ 10.1175/1520-0450(1986)025<1265:UW>2.0.CO;2.

László, E., Z. Bottyán, and S. Szegedi, 2016: Long-term changes of meteorological conditions of urban heat island development in the region of Debrecen, Hungary. Theor. Appl. Climatol., 124, 365-373, https://doi.org/10.1007/s00704-015-1427-9.

Li, M., Z. Mao, Y. Song, M. Liu, and X. Huang, 2015: Impacts of the decadal urbanization on thermally induced circulations in eastern China. J. Appl. Meteor. Climatol., 54, 259-282, https:// doi.org/10.1175/JAMC-D-14-0176.1.

Lindén, J., J. Esper, and B. Holmer, 2015: Using land cover, population, and night light data for assessing local temperature differences in Mainz, Germany. J. Appl. Meteor. Climatol., 54, 658-670, https://doi.org/10.1175/JAMC-D-14-0124.1.

Lowry, W. P., 1977: Empirical estimation of urban effects on climate: A problem analysis. J. Appl. Meteor., 16, 129-135, https://doi.org/ 10.1175/1520-0450(1977)016<0129:EEOUEO > 2.0.CO;2

Mahmood, R., and Coauthors, 2014: Land cover changes and their biophysical effects on climate. Int. J. Climatol., 34, 929-953, https://doi.org/10.1002/joc.3736.

Martin, P., Y. Baudouin, and P. Gachon, 2015: An alternative method to characterize the surface urban heat island. Int. J. Biometeor., 59, 849-861, https://doi.org/10.1007/s00484-014-0902-9.

Meentemeyer, R. K., W. Tang, M. A. Dorning, J. B. Vogler, N. J. Cunniffe, and D. A. Shoemaker, 2013: FUTURES Multilevel simulations of emerging urban-rural landscape structure using a stochastic patch-growing algorithm. Ann. Assoc. Amer. Geogr., 103, 785-807, https://doi.org/10.1080/ 00045608.2012 .707591$.
Memon, R. A., D. Y. C. Leung, and L. Chunho, 2008: A review on the generation, determination and mitigation of urban heat island. J. Environ. Sci., 20, 120-128, https://doi.org/10.1016/ S1001-0742(08)60019-4.

Mickley, L. J., P. P. Murti, D. J. Jacob, J. A. Logan, D. M. Koch, and D. Rind, 1999: Radiative forcing from tropospheric ozone calculated from a unified chemistry-climate model. J. Geophys. Res., 104, $30153-30172$, https://doi.org/10.1029/ 1999JD900439.

Mills, G., 2007: Cities as agents of global change. Int. J. Climatol., 27, 1849-1857, https://doi.org/10.1002/joc.1604.

Mohan, M., and T. A. Siddiqui, 1998: Analysis of various schemes for the estimation of atmospheric stability classification. Atmos. Environ., 32, 3775-3781, https://doi.org/10.1016/ S1352-2310(98)00109-5.

Morgan, D. L., W. O. Pruitt, and F. J. Lourence, 1971: Estimation of atmospheric radiation. J. Appl. Meteor., 10, 463-468, https:// doi.org/10.1175/1520-0450(1971)010<0463:EOAR > 2.0.CO;2.

Morris, C. J. G., I. Simmonds, and N. Plummer, 2001: Quantification of the influences of wind and cloud on the nocturnal urban heat island of a large city. J. Appl. Meteor., 40, 169-182, https://doi.org/10.1175/1520-0450(2001)040<0169: QOTIOW $>2.0 . \mathrm{CO} ; 2$.

Murphy, D. J., M. H. Hall, C. A. S. Hall, G. M. Heisler, S. V. Stehman, and C. Anselmi-Molina, 2011: The relationship between land cover and the urban heat island in northeastern Puerto Rico. Int. J. Climatol., 31, 1222-1239, https://doi.org/ 10.1002/joc.2145.

Napton, D. E., R. F. Auch, R. Headley, and J. L. Taylor, 2010: Land changes and their driving forces in the southeastern United States. Reg. Environ. Change, 10, 37-53, https://doi.org/ 10.1007/s10113-009-0084-x.

Oke, T. R., 1973: City size and the urban heat island. Atmos. Environ., 7, 769-779, https://doi.org/10.1016/0004-6981(73)90140-6. 1982: The energetic basis of the urban heat island. Quart. J. Roy. Meteor. Soc., 108, 1-24, https://doi.org/10.1002/ qj. 49710845502.

, G. T. Johnson, D. G. Steyn, and I. D. Watson, 1991: Simulation of urban heat islands under "ideal" conditions at night part 2: Diagnosis of causation. Bound.-Layer Meteor., 56, 339_ 358, https://doi.org/10.1007/BF00119211.

Ordóñez, C., A. Richter, M. Steinbacher, C. Zellweger, H. Nüß, J. P. Burrows, and A. S. H. Prévôt, 2006: Comparison of 7 years of satellite-borne and ground-based tropospheric $\mathrm{NO}_{2}$ measurements around Milan, Italy. J. Geophys. Res., 111, D05310, https://doi.org/10.1029/2005JD006305.

Peterson, T. C., 2003: Assessment of urban versus rural in situ surface temperatures in the contiguous United States: No difference found. J. Climate, 16, 2941-2959, https://doi.org/ 10.1175/1520-0442(2003)016<2941:AOUVRI > 2.0.CO;2.

Petitti, D. B., D. M. Hondula, S. Yang, S. L. Harlan, and G. Chowell, 2016: Multiple trigger points for quantifying heat-health impacts: New evidence for a hot climate. Environ. Health Perspect., 124, 176-183, https://doi.org/10.1289/ ehp.1409119.

Ren, G., and Coauthors, 2015: An integrated procedure to determine a reference station network for evaluating and adjusting urban bias in surface air temperature data. J. Appl. Meteor. Climatol., 54, 1248-1266, https://doi.org/10.1175/ JAMC-D-14-0295.1.

Roth, M., 2007: Review of urban climate research in (sub)tropical regions. Int. J. Climatol., 27, 1859-1873, https://doi.org/ 10.1002/joc.1591. 
Runnalls, K. E., and T. R. Oke, 2000: Dynamics and controls of the near-surface heat island of Vancouver, British Columbia. Phys. Geogr., 21, 283-304, doi:10.1080/02723646.2000.10642711.

Ryu, Y.-H., J.-J. Baik, and J.-Y. Han, 2013: Daytime urban breeze circulation and its interaction with convective cells. Quart. J. Roy. Meteor. Soc., 139, 401-413, https://doi.org/10.1002/qj.1973.

Sailor, D. J., and L. Lu, 2004: A top-down methodology for developing diurnal and seasonal anthropogenic heating profiles for urban areas. Atmos. Environ., 38, 2737-2748, https://doi.org/ 10.1016/j.atmosenv.2004.01.034.

Sakakibara, Y., and K. Owa, 2005: Urban-rural temperature differences in coastal cities: Influence of rural sites. Int. J. Climatol., 25, 811-820, https://doi.org/10.1002/joc.1180.

Schatz, J., and C. J. Kucharik, 2014: Seasonality of the urban heat island effect in Madison Wisconsin. J. Appl. Meteor. Climatol., 53, 2371-2386, https://doi.org/10.1175/JAMC-D-14-0107.1.

Shepherd, J. M., 2005: A review of current investigations of urbaninduced rainfall and recommendations for the future. Earth Interact., 9, https://doi.org/10.1175/EI156.1.

Simmonds, I., and K. Keay, 1997: Weekly cycle of meteorological variations in Melbourne and the role of pollution and anthropogenic heat release. Atmos. Environ., 31, 1589-1603, https://doi.org/10.1016/S1352-2310(96)00344-5.

Singh, K. K., J. B. Vogler, D. A. Shoemaker, and R. K. Meentemeyer, 2012: LiDAR-Landsat data fusion for large-area assessment of urban land cover: Balancing spatial resolution, data volume and mapping accuracy. ISPRS J. Photogramm. Remote Sens., 74, 110 121, https://doi.org/10.1016/j.isprsjprs.2012.09.009.

Steeneveld, G. J., S. Koopmans, B. G. Heusinkveld, L. W. A. van Hove, and A. A. M. Holtslag, 2011: Quantifying urban heat island effects and human comfort for cities of variable size and urban morphology in the Netherlands. J. Geophys. Res., 116, D20129, https://doi.org/10.1029/2011JD015988.

Stewart, I. D., 2011: A systematic review and scientific critique of methodology in modern urban heat island literature. Int. J. Climatol., 31, 200-217, https://doi.org/10.1002/joc.2141.

— - and T. R. Oke, 2012: Local climate zones for urban temperature studies. Bull. Amer. Meteor. Soc., 93, 1879-1900, https://doi.org/10.1175/BAMS-D-11-00019.1.

Stone, B., Jr., 2007: Urban and rural temperature trends in proximity to large US cities: 1951-2000. Int. J. Climatol., 27, 18011807, https://doi.org/10.1002/joc.1555.

Sundborg, Å., 1950: Local climatological studies of temperature conditions in an urban area. Tellus, 2 (3), 222-232, https://doi.org/ 10.3402/tellusa.v2i3.8544.

Svensson, M. K., and I. Eliasson, 2002: Diurnal air temperatures in built-up areas in relation to urban planning. Landscape Urban Plann., 61, 37-54, https://doi.org/10.1016/S0169-2046(02)00076-2.
Todhunter, P. E., 1996: Environmental indices of the Twin Cities metropolitan area (Minnesota, USA) urban heat island1989. Climate Res., 6, 59-69, doi:10.3354/cr006059.

Tumanov, S., A. Stan-Sion, A. Lupu, C. Soci, and C. Oprea, 1999: Influences of the city of Bucharest on weather and climate parameters. Atmos. Environ., 33, 4173-4183, https://doi.org/ 10.1016/S1352-2310(99)00160-0.

Turner, D. B., 1964: A diffusion model for an urban area. J. Appl. Meteor., 3, 83-91, https://doi.org/10.1175/1520-0450(1964)003<0083: ADMFAU $>2.0 . \mathrm{CO} ; 2$.

Unger, J., 1996: Heat island intensity with different meteorological conditions in a medium-sized town: Szeged, Hungary. Theor. Appl. Climatol., 54, 147-151, https://doi.org/10.1007/ BF00865157.

_ Z Z. Sümeghy, and J. Zoboki, 2001: Temperature cross-section features in an urban areas. Atmos. Res., 58, 117-127, https:// doi.org/10.1016/S0169-8095(01)00087-4.

Upmanis, H., I. Eliasson, and S. Lindqvist, 1998: The influence of green areas on nocturnal temperatures in a high latitude city (Göteborg, Sweden). Int. J. Climatol., 18, 681-700, https://doi.org/10.1002/(SICI)1097-0088(199805)18:6<681:: AID-JOC289>3.0.CO;2-L.

Vasilkov, A. P., and Coauthors, 2009: Impact of tropospheric nitrogen dioxide on the regional radiation budget. Atmos. Chem. Phys., 9, 6389-6400, https://doi.org/10.5194/acp-9-6389-2009.

Velazquez-Lozada, A., J. E. Gonzalez, and A. Winter, 2006: Urban heat island effect analysis of San Juan, Puerto Rico. Atmos. Environ., 40, 1731-1741, https://doi.org/10.1016/ j.atmosenv.2005.09.074.

Wienert, U., and W. Kuttler, 2005: The dependence of the urban heat island on latitude-A statistical approach. Meteor. Z., 14, 677-686, https://doi.org/10.1127/0941-2948/2005/0069.

Wilby, R. L., 2003: Past and projected trends in London's urban heat island. Weather, 58, 251-260, https://doi.org/10.1256/ wea.183.02.

Winkler, J. A., R. H. Skaggs, and D. G. Baker, 1981: Effects of temperature adjustments on the Minneapolis-St. Paul urban heat island. J. Appl. Meteor., 20, 1295-1300, https://doi.org/ 10.1175/1520-0450(1981)020<1295:EOTAOT >2.0.CO;2.

Wuebbles, D., and Coauthors, 2014: CMIP5 climate model analyses: Climate extremes in the United States. Bull. Amer. Meteor. Soc., 95, 571-583, https://doi.org/10.1175/ BAMS-D-12-00172.1.

Zhang, D.-L., Y.-X. Shou, R. R. Dickerson, and F. Chen, 2011: Impact of upstream urbanization on the urban heat island effects along the Washington-Baltimore corridor. J. Appl. Meteor. Climatol., 50, 2012-2029, https://doi.org/10.1175/ JAMC-D-10-05008.1. 